\title{
Motor uncoordination and neuropathology in a transgenic mouse model of Machado-Joseph disease lacking intranuclear inclusions and ataxin-3 cleavage products
}

\author{
Anabela Silva-Fernandes a,1, Maria do Carmo Costa ${ }^{\mathrm{a}, \mathrm{b}, 1}$, Sara Duarte-Silva ${ }^{\mathrm{a}, 1}$, Pedro Oliveira ${ }^{\mathrm{c}}$, \\ Claudia M. Botelho a , Luís Martins a , José António Mariz a , Tiago Ferreira ${ }^{\mathrm{d}}$, Filipa Ribeiro a \\ Margarida Correia-Neves ${ }^{a}$, Cristina Costa ${ }^{\text {, }}$, Patrícia Maciel ${ }^{\mathrm{a}, *}$ \\ a Life and Health Sciences Research Institute (ICVS), School of Health Sciences, University of Minho, Campus de Gualtar, 4710-057 Braga, Portugal \\ ${ }^{\mathrm{b}}$ Department of Neurology, University of Michigan, Ann Arbor, USA \\ c Department of Production and Systems Engineering, School of Engineering, University of Minho, Braga, Portugal \\ d Centre for Research in Neuroscience, McGill University, Quebec, Canada \\ e Department of Neurology, Hospital Prof. Fernando Fonseca, E.P.E., Amadora, Portugal
}

\section{A R T I C L E I N F O}

\section{Article history:}

Received 6 February 2010

Revised 30 April 2010

Accepted 17 May 2010

Available online $\mathrm{xxxx}$

\section{Keywords:}

Polyglutamine

Neuronal atrophy

Pathogenesis

Neuroinflammation

Spinocerebellar ataxia

Neurodegeneration

Genetic instability

Triplet repeats

\begin{abstract}
A B S T R A C T
Machado-Joseph disease (MJD) is a late-onset neurodegenerative disorder caused by a polyglutamine (polyQ) expansion in the ataxin-3 protein. We generated two transgenic mouse lineages expressing the expanded human ataxin-3 under the control of the CMV promoter: CMVMJD83 and CMVMJD94, carrying Q83 and Q94 stretches, respectively. Behavioral analysis revealed that the CMVMJD94 transgenic mice developed motor uncoordination, intergenerational instability of the CAG repeat and a tissue-specific increase in the somatic mosaicism of the repeat with aging. Histopathological analysis of MJD mice at early and late stages of the disease revealed neuronal atrophy and astrogliosis in several brain regions; however, we found no signs of microglial activation or neuroinflammatory response prior to the appearance of an overt phenotype. In our model, the appearance of MJD-like symptoms was also not associated with the presence of ataxin-3 cleavage products or intranuclear aggregates. We propose the transgenic CMVMJD94 mice as a useful model to study the early stages in the pathogenesis of MJD and to explore the molecular mechanisms involved in CAG repeat instability.
\end{abstract}

(c) 2010 Elsevier Inc. All rights reserved.

\section{Introduction}

Machado-Joseph disease (MJD), also known as Spinocerebellar Ataxia type 3 (SCA3), is an autosomal dominant neurodegenerative disorder caused by the expansion of a polyglutamine tract (polyQ) in the C-terminus of the ATXN3 gene product, ataxin-3 (ATXN3) (Kawaguchi et al., 1994). In this gene, the polyQ tract length ranges between 12 and 44 in the normal population and between 53 and 87 in patients (Maciel et al., 2001; van Alfen et al., 2001).

Clinically, MJD is characterized by a late-onset spinocerebellar ataxia, ophthalmoplegia and spasticity associated to variable degree with amyotrophy or extrapyramidal features (Coutinho and Andrade, 1978). The pathological hallmark of the disease is the presence of nuclear inclusions of aggregation-prone expanded

\footnotetext{
* Corresponding author. Fax: + 351253604820.

E-mail address: pmaciel@ecsaude.uminho.pt (P. Maciel).

1 These authors contributed equally to this work.

Available online on ScienceDirect (www.sciencedirect.com).
}

ATXN3 in the patients' brains. Although ATXN3 is ubiquitously expressed (Paulson et al., 1997), only restricted neuronal populations of the central nervous system (CNS) are classically described as affected, namely the cerebellar dentate nucleus, pallidum, substantia nigra, thalamus, subthalamic, red, and pontine nuclei, cranial nerve nuclei and the anterior horn and Clarke's column of the spinal cord (Romanul et al., 1977; Rosenberg et al., 1976; Woods and Schaumburg, 1972). Recent pathological studies have suggested that the extension of CNS degeneration in MJD patients at end stages may be more widespread, including the visual, auditory, vestibular, somatosensory, ingestion-related, dopaminergic and cholinergic systems (Rub et al., 2008).

Fifteen years have passed since the cloning of the MJD causative gene (Kawaguchi et al., 1994), and to date the mechanism of cell demise taking place in specific regions of the brains of MJD patients remains largely ignored. However, the numerous studies of polyQ and other neurodegenerative diseases undertaken during these years have raised important questions: i) How are neurons dying: is active cell death occurring, or is necrosis the main pathway of death? ii) What is the contribution of somatic mosaicism in cell-specific vulnerability? 
iii) Which are the toxic species: the aggregated, cleaved or soluble forms of ataxin-3? iv) What is the role of neuroinflammation in the disease process?

To attempt to answer these questions, several transgenic mouse models of MJD were created using different promoters to drive the expression of the human cDNA/gene: the L7 specific Purkinje cell promoter (Ikeda et al., 1996); the ATXN3 promoter (Cemal et al., 2002); the HD promoter (Boy et al., 2009a); and different portions of the $\operatorname{PrP}$ promoter (which originates high brain expression levels) (Bichelmeier et al., 2007; Chou et al., 2008; Goti et al., 2004). More recently, a conditional MJD mouse model using the Tet-Off system was described showing reversibility of the phenotype (Boy et al., 2009b).

Although the most central questions still remain unanswered, these mouse models provide excellent mammalian systems to be used in the study of MJD pathogenesis. In this study, we have generated and characterized a new transgenic mouse model in which the human cDNA is ubiquitously expressed under the regulation of the cytomegalovirus promoter (pCMV). This mouse model mimics some key features of MJD including the ataxia and the dynamics of the CAG repeat, and we used it to study the cellular pathway(s) involved in cell death and the potential role of neuroinflammation in MJD pathogenesis.

\section{Methods}

\section{Generation of CMVMJD transgenic mice}

To generate transgenic MJD mice, the cDNA ATXN3c variant (GenBank accession no. U64820.1) (Goto et al., 1997) carrying a repeat tract (CAG) ${ }_{2}$ CAAAAGCAGCAA(CAG) $)_{77}$ coding for 83 glutamines was amplified by PCR, introducing $5^{\prime}$ and $3^{\prime}$ flanking NotI restriction sites, and then cloned into the pCMV vector (kindly provided by Dr. Mónica Sousa, Univ. Porto). This plasmid, designated as pCMVMJD1-1E, was linearized by partial digestion with PstI (Fermentas), the fragment of interest (3150 bp) was then purified from an agarose gel using the QiaQuick gel extraction system (Qiagen, Hamburg, Germany) and microinjected into fertilized murine oocytes of the $\mathrm{FVB} / \mathrm{N}$ mouse strain (Eurogentec, Seraing, Belgium). Two female founders were obtained from two different microinjections, establishing the transgenic CMVMJD94 and CMVMJD83 mouse lineages, which were backcrossed with C57Bl/ 6 mice (Harlan Iberica, Barcelona, Spain) over nine and seven generations, respectively. Hemizygous, homozygous CMVMJD transgenic mice (hemi CMVMJD and homo CMVMJD, respectively) and control littermates were obtained from colony inbreeding.

\section{Animals}

All animals were maintained under standard laboratory conditions: an artificial $12 \mathrm{~h}$ light/dark cycle (lights on from 8:00 to 20:00 h), with an ambient temperature of $21 \pm 1{ }^{\circ} \mathrm{C}$ and a relative humidity of $50-60 \%$; the mice were given a standard diet (4RF25 during the gestation and postnatal periods, and 4RF21 after weaning, Mucedola SRL, Settimo Milanese, Italy) and water ad libitum. Health monitoring was performed according to FELASA guidelines (Nicklas et al., 2002), confirming the Specified Pathogen Free health status of sentinel animals maintained in the same animal room. All procedures were conducted in accordance with European regulations (European Union Directive 86/609/EEC). Animal facilities and the people directly involved in animal experiments (ASF, MCC, SS, CB) were certified by the Portuguese regulatory entity - Direcção Geral de Veterinária. All of the protocols performed were approved by the joint Animal Ethics Committee of the Life and Health Sciences Research Institute, University of Minho, and the Institute for Molecular and Cell Biology, University of Porto.

\section{Mouse genotyping}

DNA was isolated from tail biopsy using the Puregene DNA isolation kit (Gentra Systems, Minneapolis, MN). In this single PCR genotyping tube, the primers TR1 (5'-GAAGACACCGGGACCGATCCAG$\left.3^{\prime}\right)$ and TR2 (5'-CCAGAAGGCTGCTGTAAAAACGTGC-3') were used to amplify the transgene $(454 \mathrm{bp})$, and the primers mmMJD8 (5'CAAAGTAGGCTTCTCGTCTCCT-3') and mmMJD24 (5'-AGTGCTGAGAACACTCCAAG-3') to amplify the mouse homologous Atxn3 gene (800 bp) as an internal control for the PCR. Hemizygosity/homozygosity and the transgene copy number were discriminated by semiquantitative PCR, in which the transgene was amplified using the pair of primers TR1/TR2, and an intronic fragment (546 bp) of the mouse homologous gene Atxn3 was amplified, as a reference gene (number of copies), using the primers mmMJD89 (5'-GCTAGCTAGAGCTACTTATTG-3') and mmMJD54 (5'-GACTCCAGAGAGCACCTG-3'). Briefly, to determine the number of cycles in which the amplification was at the middle of the exponential phase, a sequential series of PCRs using both pairs of primers were performed for each lineage of transgenic mice. Gels were visualized with AlphaImager 2200 (AlphaInnotech, San Leandro, CA, USA) and analyzed by densitometry with the corresponding AlphaEase software.

\section{Molecular analysis of the $(C A G)_{n}$ repeat}

The analysis of the intergenerational instability of the repeat was assessed in two different genetic backgrounds, $\mathrm{FVB} / \mathrm{N}$ and $\mathrm{C} 57 \mathrm{Bl} / 6$, in male $(n=22, n=32)$ and female meioses $(n=24, n=18)$. The repeat tract (CAG) $)_{2}$ CAAAAGCAGCAA(CAG) $\mathrm{X}$ and a 75-bp flanking region of the ATXN3 gene were amplified by PCR using the primers MJD25a (5'GGCTGGCCTTTCACATGGAT-3') and MJDcDNA (5'-CGGAAGAGACGAGAAGCCTAC-3').

The relative $(C A G)_{n}$ size variation across generations was studied by PCR amplification of DNA extracted from tail biopsies using the primers described above and incorporation of $\left[{ }^{35} \mathrm{~S}\right]$ dATP (Amersham). PCR products were loaded in a denaturating $6 \%$ polyacrylamide gel as previously described (Maciel et al., 2001). The major allele size was determined by densitometry using AlphaEase software to detect the peak with the highest height in the AlphaImager 2200 (AlphaInnotech). CAG repeat length variation was determined by comparison with the highest height peak band from PCR products generated from progenitor DNAs.

For the analysis of the repeat in different tissues, hemi CMVMJD94 transgenic males with $5(n=3), 24(n=5), 60(n=6)$ and $72(n=4)$ weeks of age, were transcardially perfused with PBS under anaesthesia (ketamine hydrochloride $(150 \mathrm{mg} / \mathrm{kg}$ ) plus medetomidine $(0.3 \mathrm{mg} / \mathrm{kg}))$ and tissues were rapidly removed, frozen in dry ice and stored at $-80^{\circ} \mathrm{C}$. DNA extraction from brain regions (cerebellar cortex, deep cerebellar nuclei, motor cortex, hippocampus, amygdala, hypothalamus, substantia nigra, striatum and pontine nuclei) and peripheral tissues (heart, skeletal muscle, testis, kidney, liver and tail) was performed using the Puregene DNA isolation kit (Gentra Systems). Somatic mosaicism was studied in the transgenic mice by determination of the CAG repeat number using the same PCR strategy as described above, except for the usage of a 6-FAM fluorescently labeled MJDcDNA primer. Products were displayed in an ABI 310 automated DNA sequencer (Applied Biosystems, Foster City, CA). The degree of mosaicism of different tissues of mutant mice was analyzed by calculating the mosaicism index (MI). In order to avoid inclusion of PCR artifacts, only bands larger than the major bands were taken into account (Cancel et al., 1998). The number of bands with peak areas of at least $10 \%$ of the major band was counted and their surfaces summed. MI was defined as the ratio between this sum and the area of the major size band. The CAG tract length of the major size band was determined using an equation from the calibration curve obtained 
with cloned alleles containing known numbers of CAG repeats (Williams et al., 1999).

\section{Transgene expression analysis}

Anaesthetized animals ( $n=3$ or 4 for each genotype) were euthanized by transcardial perfusion with PBS, tissues were collected, frozen in dry ice and stored at $-80{ }^{\circ} \mathrm{C}$. For protein isolation, mouse tissues were homogenized in 5 volumes of cold resuspension buffer (RB): 0.1 M Tris- $\mathrm{HCl}, \mathrm{pH}$ 7.5, 0.1 M EDTA, $0.4 \mathrm{mM}$ PMSF and a mixture of protease inhibitors (Roche, Indianapolis, IN). Protein concentrations were determined using the Bradford protein assay (Bio-Rad, Hercules, CA, USA), and samples were diluted in RB and Laemmli sample buffer at a final concentration of $2.5 \mathrm{mg} / \mathrm{ml}$. Samples were sonicated for $10 \mathrm{~s}$, heated for $3 \mathrm{~min}$ at $100{ }^{\circ} \mathrm{C}$ and centrifuged for $10 \mathrm{~s}$ before loading $20 \mu \mathrm{l}$ per sample in $10 \%$ SDS-PAGE minigels. The blots were blocked in $5 \%$ dry milk/PBS before incubation overnight at $4{ }^{\circ} \mathrm{C}$ with the primary antibody: serum anti-ataxin-3 (kindly provided by Dr. Henry Paulson) $(1: 20,000), 1 \mathrm{H} 9$ (1:2000) or anti-GAPDH (Advanced ImmunoChemical. Inc., Long Beach, CA, USA) (1:500). Bound primary antibodies were visualized with goat anti-mouse or goat anti-rabbit HRP-conjugated secondary antibodies at 1:500 (PIERCE, Rockford, IL), chemiluminescent substrate (PIERCE), and exposure on autoradiography films (Amersham, Uppsala, Sweden). Signal bands were quantified using the ImageJ Software.

Total RNA from wild-type or CMVMJD mice ( $n=4$ or 5 ) brain tissue was isolated using TRIZOL (Invitrogen, Calrsbad, CA, USA) according to the manufacturer's protocol. First-strand cDNA synthesized using oligo-dT was amplified by quantitative reverse-transcriptase PCR (qRT-PCR) using primers in the 3' UTR region to detect specifically human and mouse ataxin-3 mRNA (MJD_UTR1b_r: 5' GCCCTAACTTTAGACATGTTAC3'; MJD_UTR3_F: 5'GGAACAATGCGTCGGTTG3'; mjd_3UTR_2r: 5'GTTACAAGAACAGAGCTGACT3'; mjd_3UTR_1f: 5'TGTCTTGTTACAGAAAGATCAG3'). Primer specificity was controlled by two negative PCR reaction controls: one with the primers for mouse ataxin-3 mRNA using the pCMVMJD1-1E plasmid (carrying the human cDNA) as template; and the other with the primers for human ataxin-3 mRNA and a total cDNA template from a wild-type mouse.

\section{Immunohistochemistry}

Transgenic (hemi and homozygotes) and control non-transgenic littermate mice ( $n=4$ or 5 for each group) at different ages $(16,49$ and 84 weeks) were deeply anaesthetized and transcardially perfused with PBS followed by $4 \%$ paraformaldehyde (PFA) in PBS. Brains were post-fixed overnight in fixative solution and embedded in paraffin. Slides with 4 - $\mu \mathrm{m}$-thick paraffin sections were steamed for antigen retrieval and then incubated with rabbit GFAP antibody (DAKO Corporation, Carpinteria, CA) (1:500) or rabbit anti-MJD1.1 (Ferro et al., 2007) (1:40). A biotinylated secondary antibody was applied, followed by $A B C$ coupled to horseradish peroxidase (DAKO) and DAB substrate (Vector Laboratories Inc., Burlingame, CA, USA). The slides were counterstained with hematoxylin according to standard procedures and analyzed with an optical microscope (Olympus, Hamburg, Germany). For morphological brain analysis, we performed hematoxylin \& eosin and cresyl violet staining. The stereological analysis of GFAP-positive cells was performed in the vestibular region and in the substantia nigra using StereoInvestigator software (MicroBrightField, Williston/VT, USA). From each set of serial sections, 2 photomicrographs of the areas of interest were obtained at a primary magnification of $\times 25$ and analyzed at a final magnification of $\times 1000$. Measurements were performed on regions randomly selected by the software. The densitometric analysis was performed in Purkinje cells, locus coeruleus, dentate nuclei and substantia nigra using a Zeiss light microscope coupled to a PC, using NIH Image 1.52 software. Density levels were quantified and, for all sections, background density measurements were subtracted to these values.

For anti-Iba-1 immunohistochemistry, brains from hemi CMVMJD94 mice and littermates at 10 and 25 weeks of age $(n=3$ per group) were fixed in a $4 \%$ PFA/PBS solution for 3 days, after which they were kept in an $8 \%$ sucrose solution. Forty-micron-thick vibratome sections were incubated with rabbit anti-Iba-1 (Wako chemicals, 019-19741) (1:250). The antibodies were detected as above, as was the counterstaining and visualization of the slides.

Apoptosis was analyzed using the TUNEL assay. In situ DNA endlabeling was accomplished using the Apoptag Peroxidase In situ Apoptosis Detection Kit (Chemicon International, USA) according to the manufacturer's instructions. Mice were deeply anaesthetized, transcardially perfused with PBS and brains were removed and frozen at $-80{ }^{\circ} \mathrm{C}$ embedded in OCT. Frozen brain sections $(10 \mu \mathrm{m})$ of transgenic CMVMJD94 and wild-type mice ( $n=4$ for each genotype) with 86 to 100 weeks of age, were fixed in $1 \%$ PFA/PBS for $30 \mathrm{~min}$ and post-fixed in pre-cooled ethanol:acetic acid $(2: 1)$ at $-20{ }^{\circ} \mathrm{C}$ for $5 \mathrm{~min}$. Endogenous peroxidase was inactivated by immersing the tissue sections in $3 \% \mathrm{H}_{2} \mathrm{O}_{2}$ in PBS solution for $30 \mathrm{~min}$ and rinsing several times with water and PBS.

For caspase-3 detection, frozen sections of the same experimental group used for TUNEL assay, were fixed in 4\% PFA/PBS and incubated with rabbit anti-active-caspase-3 (R\&D systems AF835, 1:250, diluted in TBS) overnight at $4{ }^{\circ} \mathrm{C}$. The detection of active-caspase- 3 was assessed according to the streptavidin-biotin peroxidase complex system (Ultra Vision Large Volume Detection System Anti-Polyvalent, HRP; Lab Vision Corporation, Fremont, CA, USA) according to the manufacturer's instructions.

Fluoro-jade B staining was also performed in the animals group described above, to evaluate the presence of non-apoptotic cell death according to the manufacturer's instructions (Chemicon International).

\section{Phenotype analysis}

Behavioral analysis was performed during the diurnal period in groups of 5 animals per cage of CMVMJD83 and CMVMJD94 transgenic mice (hemi and homo) and wild-type littermates $(n=10$ per genotype and gender). Animals were evaluated at 16, 24, 36, 48, 60,72 and 84 weeks of age in the Rotarod followed by the SHIRPA protocol.

\section{SHIRPA protocol}

We established a protocol for phenotypic assessment based on the primary screen of the SHIRPA protocol, which mimics the diagnostic process of general neurological and psychiatric examination in humans (Rogers et al., 1997). Each mouse was placed in a viewing jar (15 cm diameter) for $5 \mathrm{~min}$, transferred to a 15-labeled-squares arena $(55 \times 33 \times 18 \mathrm{~cm})$, and then a series of anatomical and neurological measures were determined. The full details of the SHIRPA protocol are available at the site: http://www.mgu.har.mrc. ac.uk/facilities/mutagenesis/mutabase/shirpa_summary.html.

In addition, we included the vertical pole test (Wallace et al., 1980), the footprint pattern test (Carter et al., 1999) and the counting of rears over $5 \mathrm{~min}$ in the viewing jar as a measure of spontaneous exploratory activity. The protocol was adjusted in order to minimize animal handling and to generate uniformity in waiting times between the tests (Rafael et al., 2000).

\section{Vertical pole test}

This test was performed on a wood pole of approximately two $\mathrm{cm}$ in diameter and 40-cm long, wrapped with cloth tape for improved traction. The mouse was placed in the center of the pole, held horizontally, and then the pole was gradually lifted to a vertical 
position. Latency to fall off the pole was recorded with a maximum time of $1 \mathrm{~min}$.

\section{Footprint pattern}

The footprint test was used to evaluate the gait of the animals. To obtain footprints, the hind- and forepaws of the mice were coated with black and red non-toxic paints, respectively. A clean sheet was placed on the floor of the runway for each run. The animals were then allowed to walk along a $100-\mathrm{cm}$-long $\times 4.2 \mathrm{~cm}$ width $\times 10 \mathrm{~cm}$ height corridor in the direction of an enclosed black box. Each animal was allowed to achieve one valid trial per age. The footprint patterns were analyzed for four step parameters (all measured in $\mathrm{cm}$ ): the front- and hind-base width, the foot step uniformity and the length of the step. For each step parameter, three values were measured for three consecutive steps, with the exclusion of the first four steps to allow for habituation.

\section{Rotarod}

Mice were tested in a rotarod apparatus (TSE systems, Bad Homburg, Germany) to evaluate their motor performance. The protocol consisted of 3 days of training at a constant speed (15 rpm) for a maximum of $60 \mathrm{~s}$ in four trials, with a 10 min interval between each trial. On the fourth day, animals were tested for each of 6 different speeds ( $5 \mathrm{rpm}, 8 \mathrm{rpm}, 15 \mathrm{rpm}, 20 \mathrm{rpm}, 24 \mathrm{rpm}$ and $31 \mathrm{rpm}$ ) for a maximum of $60 \mathrm{~s}$ in two trials, with a 10 -min-long interval between each trial. After a one-hour rest period, the animals were subjected to four trials on an acceleration rod (4-40 rpm, 5 min) with a 10-15-long interval between each trial.

\section{$R T^{2}$ ProfilerTM PCR Array (Superarray) analysis of neuroinflammation}

The mRNA expression level of 84 key genes involved in the inflammatory response, 5 house-keeping genes and controls for DNA contamination, reverse transcription and PCR efficiency were determined simultaneously using Superarray technology (SABiosciences ${ }^{\mathrm{TM}}$ ). For this experiment, animals were euthanized by decapitation, and the cerebellum was collected and immediately snap frozen and stored at $-80^{\circ} \mathrm{C}$. RNA samples extracted from the cerebellum of CMVMJD94 transgenic and wild-type animals at 8 and 24 weeks of age $(n=10$ or 12) were pooled onto individual Superarrays with 3-4 samples per array for a total of 3 arrays per condition. The RNA was first converted into first-strand cDNA using the $\mathrm{RT}^{2}$ First Strand Kit following the manufacturer's guidelines. In addition, we analyzed the expression levels of the tumor necrosis factor (Tnfo), interleukin 6 (Il6), interleukin 1 beta (Il1 $\beta$ ) and ionized calcium-binding adapter molecule 1 (Iba-1) genes by the qRT-PCR assay using the following primers, respectively: mu Tnfa Sy F (5'GCCACCACGCTCTTCTGTCT3'); mu Tnfa Sy R (5' TGAGGGTCTGGGCCATAGAAC $3^{\prime}$ ); mu Il-6 Sy F (5'ACACATGTTCTCTGGGAAATCGT3'); mu Il-6 Sy R (5'AAGTGCATCATCGTTGTTCATACA3'); SP_Il-1b (5'ACCTTCCAGGATGAGGACATGA3'); AS_Il-1b (5'AACGTCACACACCAGCAGGTTA3'); Iba-1_f (5'GAAGCGAATGCTGGAGAAAC3'); Iba-1_r (5'CTCATACATCAGAATCATTCTC3').

\section{Statistical analysis}

Behavioral data were subjected to the non-parametric MannWhitney $U$-test when variables were non-continuous or when a continuous variable did not present a normal distribution (Kolmogorov-Smirnov test $p<0.05$ ). Continuous variables with normal distributions (K-S test $p>0.05$ ) were analyzed with the Student $t$-test or ANOVA. All statistical analyses were performed using SPSS 16.0 (SPSS Inc., Chicago, IL). A critical value for significance of $p<0.05$ was used throughout the study.

\section{Results and discussion}

We have created a novel transgenic mouse model of MJD expressing an expanded version of the human MJD1-1 cDNA (the 3 UIMs-containing variant of ATXN3, previously used in the mouse models described by Bichelmeier et al., 2007; Boy et al., 2009a,b), under the regulation of the CMV promoter. This model displays some important features that mirror the human disease. Transgenic CMVMJD94 mice (94 CAGs) showed: i) a motor uncoordination phenotype that, manifested in hemizygous mice, is in agreement with the dominant mode of transmission of this spinocerebellar ataxia; ii) a direct correlation between CAG repeat length and disease manifestation; iii) intergenerational instability of the (CAG) $)_{\mathrm{n}}$ tract; iv) somatic mosaicism of the repetitive CAG stretch in neuronal and non-neuronal tissues; and v) neuropathologic alterations in specific regions such as the thalamus, the dentate and pontine nuclei, the substantia nigra and the vestibular nuclei, that parallel the human disorder. Importantly, the detailed study of this model allowed us to exclude events such as ATXN3 cleavage and intranuclear aggregation as key factors to the onset of disease and revealed that neurodegeneration occurs in the absence of apoptosis or necrosis. Neuroinflammation was also not evident at the early stages of the disease.

\section{Generation of MJD transgenic mice}

In order to generate MJD transgenic mice, we subcloned the mutant human cDNA ATXN3c variant carrying a (CAG) ${ }_{2}$ CAAAAGCAGCAA $(\mathrm{CAG})_{77}$ repeat tract, coding for 83 polyQs, into the pCMV vector, which is a strong and general expression promoter (Fig. 1A). Two founders were obtained from two different microinjections: founder CMVMJD94 and CMVMJD83, carrying 94 and 83 CAGs, respectively (Fig. 1B). This indicates that the CAG repeat tract from founder CMVMJD94 suffered an expansion of 11 CAG repeats from the injected construct, probably occurring during early embryonic mitosis events. Our analysis of the transmission of the transgene revealed an adequate fit to Mendelian expectations, with no decrease of the proportion of homozygotes (Fig. 1B). Although a Mendelian segregation distortion for the expanded CAG allele (with a higher transmission of the mutant allele) has been described by some authors in human MJD families (Ikeuchi et al., 1996; Iughetti et al., 1998; Riess et al., 1997; Takiyama et al., 1997), this is a controversial finding that, according to others, can be explained by observational bias in families selected for genetic lineage studies due to a large number of affected individuals (Grewal et al., 1999). Our analysis of the transmission of the CMVMJD94 and CMVMJD83 transgenic lineages excluded a "meiotic drive" effect of the expanded allele in these mice (Fig. 1B).

\section{Expression of expanded human ataxin-3}

As expected from the general expression features of the pCMV promoter, the human ataxin-3 (ATXN3) was detected in the CNS (Fig. 1C) and peripheral tissues of transgenic mice in both lineages by anti-ataxin-3 western blot and immunohistochemistry (IHC). This is comparable to the ubiquitous expression of ATXN3 reported in human tissues (Kawaguchi et al., 1994; Paulson et al., 1997). The ATXN3 mRNA expression was also confirmed in both lineages by qRT-PCR (data not shown).

In the immunoblots for both lineages endogenous mouse ataxin-3 protein (Atxn3) was observed at $42 \mathrm{kDa}$, as previously described (Costa et al., 2004), while ATXN3 was detected at approximately $70 \mathrm{kDa}$; due to the CAG tract length difference it was possible to observe a slight variation in the ATXN3 protein size between CMVMJD94 and CMVMJD83 transgenic mice (Fig. 1C). No SDSresistant species or cleaved products of ATXN3 were observed in the brains of mice from either transgenic lineage (Fig. 1D). Quantitative measurement of these immunoblots confirmed that CMVMJD94 
A

\begin{tabular}{|c|c|c|c|c|c|}
\hline $\begin{array}{c}\text { CMV } \\
\text { promoter }\end{array}$ & 粘 & MJD1-1 cDNA & $\begin{array}{l}\text { 등 } \\
\text { g }\end{array}$ & 敚 & $\begin{array}{c}\text { Poly (A) } \\
\text { SV40 }\end{array}$ \\
\hline
\end{tabular}

B

\begin{tabular}{lllllll} 
Construct & Repeat motif & Founder & $\begin{array}{l}\text { Frequency of } \\
\text { transmission }\end{array}$ & $\begin{array}{l}\text { Repeat tract } \\
\text { length }\end{array}$ & $\begin{array}{l}\text { Transgene } \\
\text { copy number }\end{array}$ & $\begin{array}{l}\text { ATXN3 brain expression } \\
\text { (ATXN3/GAPDH ratio) }\end{array}$ \\
\hline \multirow{2}{*}{ PCMVMJD1-1E } & $($ (CAG)2CAAAAGCAGCAA(CAG) $)$ & CMVMJD94 & $56 \%(\mathrm{~N}=88)$ & 94 & 2 & hemizygous: 0.55 \\
\cline { 3 - 7 } & CMVMJD83 & $52 \%(\mathrm{~N}=121)$ & 83 & 5 (aprox) & $\begin{array}{l}\text { hemizygous: } 0.43 \\
\text { homozygous: } 0.63\end{array}$ \\
\hline
\end{tabular}

C

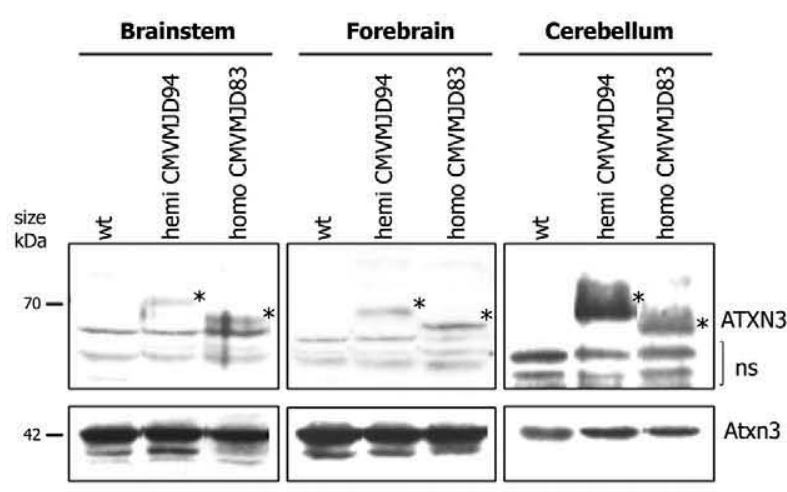

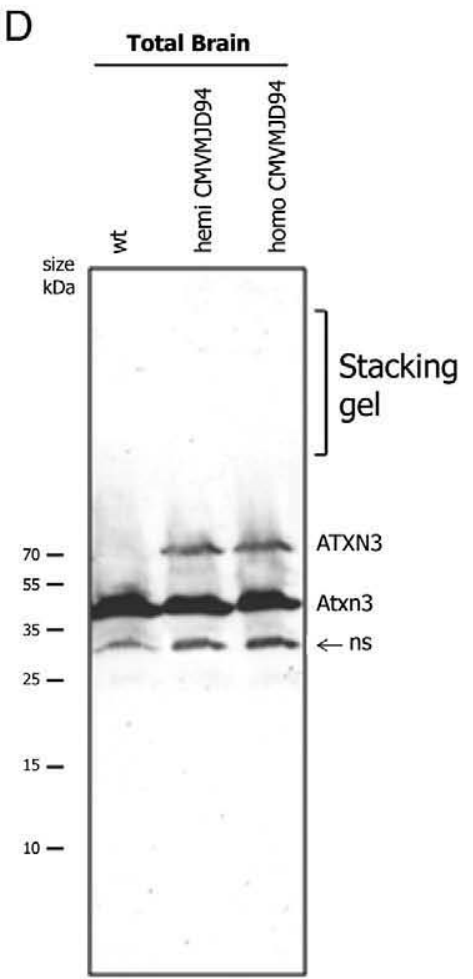

Fig. 1. Mendelian transmission of the transgene and ubiquitous brain expression of ATXN3 in CMVMJD transgenic mice. (A) Schematic diagram of the plasmid CMVMJD1-1E used for the generation of CDNA MJD transgenic mice. (B) Descriptive summary of the transgenic mouse lineages generated. (C) Western blot analysis of human ataxin-3 (ATXN3) in different CNS regions of CMVMJD83 and CMVMJD94 mice with approximately 86 weeks of age. In all lanes, the endogenous mouse ataxin-3 (Atxn3) is detected at about 42 kDa. An approximately 70-kDa protein (asterisks) corresponding to expanded ATXN3 is detected in transgenic animal lysates from the cerebellum, forebrain and brainstem. Hemi CMVMJD94 animals and homo CMVMJD83 express approximately equal levels of ATXN3. (D) Western blot using 1H9 antibody for CMVMJD94 mice at advanced ages (84 weeks of age) did not reveal the presence of ATXN3 fragments or insoluble protein in the stacking gel. wt, wild-type; hemi, hemizygous; homo, homozygous; ns, non-specific bands.

hemizygotes and CMVMJD83 homozygotes mice expressed approximately equal levels of ATXN3 in total brain (Fig. 1B). As a control result, we observed that ATXN3 expression in homozygous mice was double that of hemizygous mice (Fig. 1D). In addition, ATXN3 was also detected in peripheral tissues and organs such as skeletal muscle, pancreas, heart and testis of both mutant lines (data not shown).

Anti-ataxin-3 IHC revealed increased ATXN3 expression in transgenic MJD mice brains, both in terms of intensity and number of stained cells, in comparison with non-transgenic littermates (Fig. 2; Supp. Figure 1). In addition, mutant ATXN3 was detected in several brain regions including areas involved in MJD, namely, the cerebellum (cerebellar cortex and deep cerebellar nuclei), the pontine nuclei, the locus coeruleus and the substantia nigra, among others (Fig. 2).

Parental gender and genetic background-dependent pattern of CAG intergenerational instability

A common feature of polyQ disorders is the dynamic behavior of CAG expansions, which are thought to be responsible for the anticipation observed in human patients. This phenomenon reflects the global tendency of expanded repeats to become larger when transmitted from one generation to the next. CAG repeat length variation is observed not only throughout generations - intergenerational instability - but also among several tissues of individual patients - somatic mosaicism. To investigate whether MJD transgenic mice, like human patients, displayed intergenerational instability of the expanded triplet repeat, we determined the $(C A G)_{n}$ tract length in maternal and paternal meioses of transgenic CMVMJD94 animals. This lineage was chosen for the study because amplification of the CAG repeat produces a single major peak. This finding means that the two copies of the transgene integrated in these transgenic mice carry the same CAG repeat number, allowing the analysis of $(C A G)_{n}$ length variation. When amplified by PCR, the DNA extracted from transgenic mouse tissues exhibited a pattern of bands very similar to that observed in heterozygous human patients (Maciel et al., 1997).

These mice were generated by breeding between either hemi CMVMJD94 males or females with the correspondent non-transgenic breeder in two different genetic backgrounds, $\mathrm{C} 57 \mathrm{Bl} / 6$ and $\mathrm{FVB} / \mathrm{N}$, 


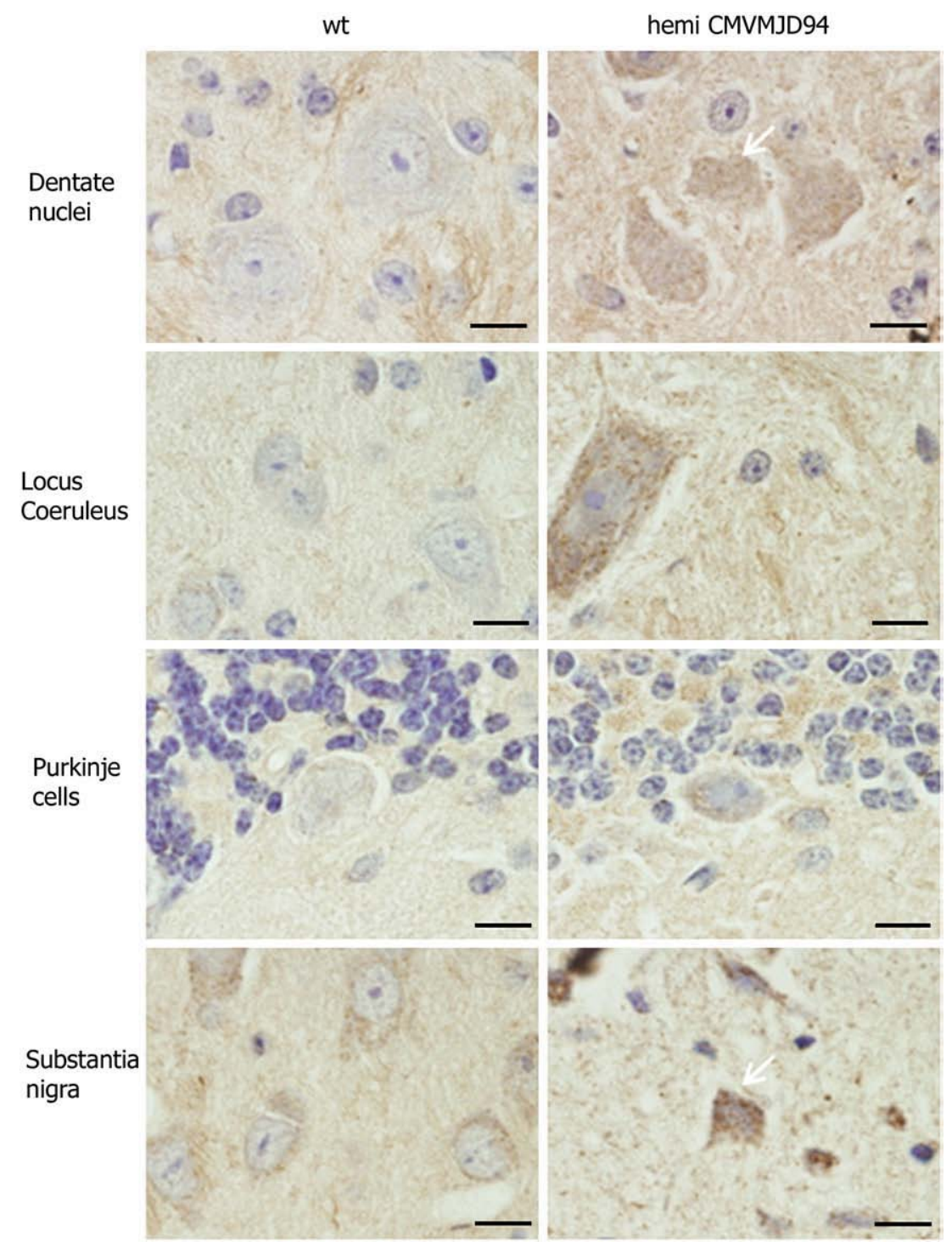

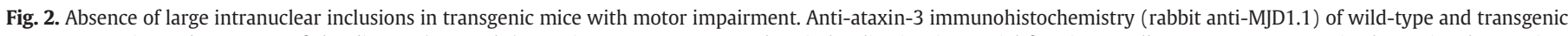

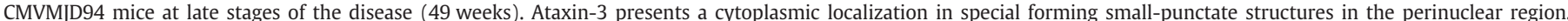

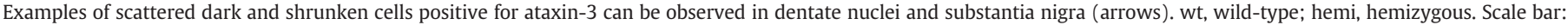
$10 \mu \mathrm{m}$.

which allowed us to identify genetic background effects on repeat instability. We observed, for both backgrounds, that the CAG repeat length varied through generations in more than $50 \%$ of the transmissions: the expanded allele had the tendency to expand when transmitted through the male progenitor and to contract when transmitted from the female progenitor (Figs. 3A,B). This observation reached statistical significance in the $\mathrm{C} 57 \mathrm{Bl} / 6$ background $(p<0.05)$ (Fig. 3B). The differential distribution of CAG repeat length variation in the two congenic strains suggests that backgroundspecific modifier loci might affect the pattern of instability of this CAG tract.

Our results are in agreement with previous results described in MJD patients regarding the mild instability of the CAG tract length and the difference in $(\mathrm{CAG})_{\mathrm{n}}$ instability between male and female transmissions (Maciel et al., 1995).

\section{CAG length-dependent motor phenotype}

During the behavioral analysis period, some animals with different genotypes died, without bias. Behavioral studies revealed a number of findings in the CMVMJD94 transgenic mice, which differed from nontransgenic and transgenic hemizygous or homozygous mice from lineage CMVMJD83. The rotarod test performed either at constant speeds or using an acceleration protocol revealed that both hemi and homo CMVMJD94 mice presented a motor coordination impairment beginning at 16 weeks of age (Fig. 4A). In MJD, a gene-dosage effect has been proposed in individuals who are homozygous for the mutation, showing a juvenile onset and more rapid progression of the disease (Sobue et al., 1996). Interestingly, in our model, homozygous animals also spent less time on the rod in comparison with hemizygous animals, although this difference did not reach statistical significance (Fig. 4A).

Additionally, transgenic CMVMJD94 mice presented a trend towards a decrease of locomotor activity, given by the number of squares traveled in the arena in the SHIRPA protocol (Fig. 4B). This reduced locomotor activity only reached significance for homozygous animals at 48 weeks of age (Fig. 4B). No differences were found for the other parameters evaluated, including the vertical pole test and the footprinting pattern (Supp. Figure 2). Hemi or homo CMVMJD83 mice, differing from the CMVMJD94 in the CAG tract, which was only 11 
A
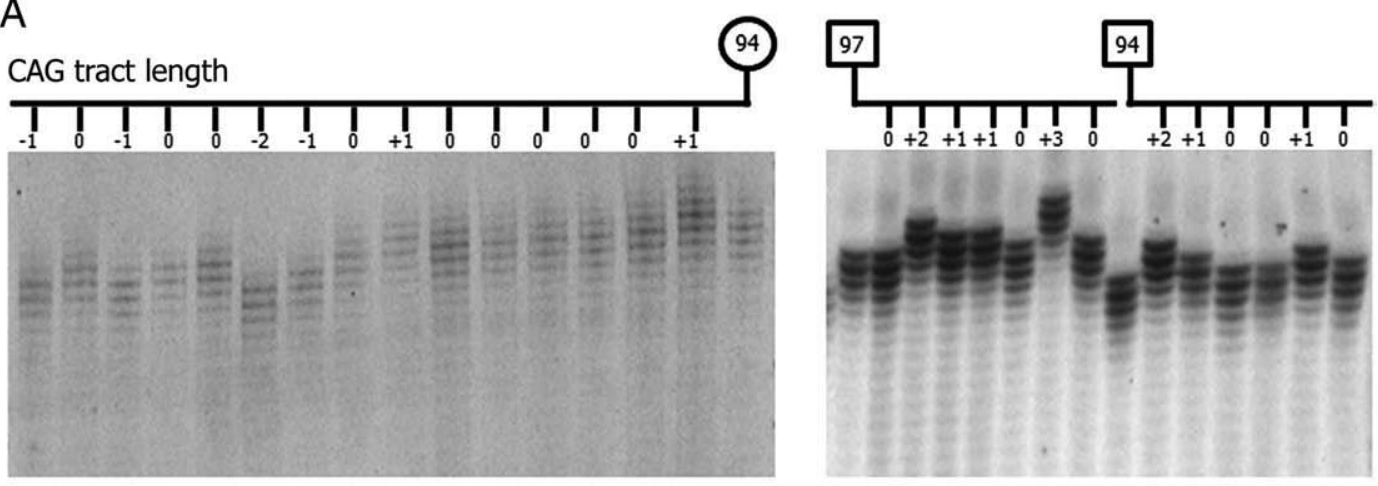

B

$\mathrm{FVB} / \mathrm{N}$

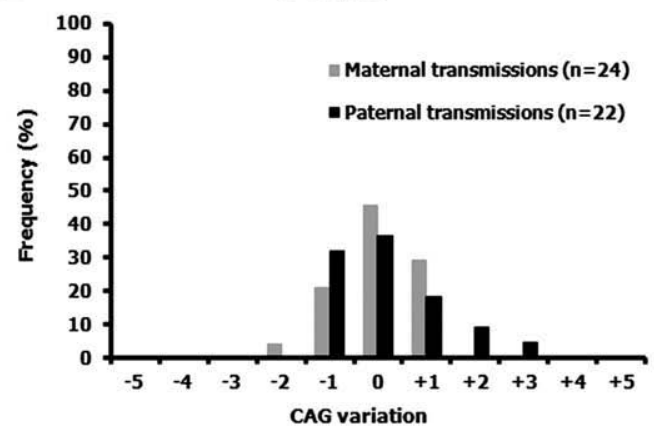

$\mathrm{C} 57 \mathrm{BI} / 6$

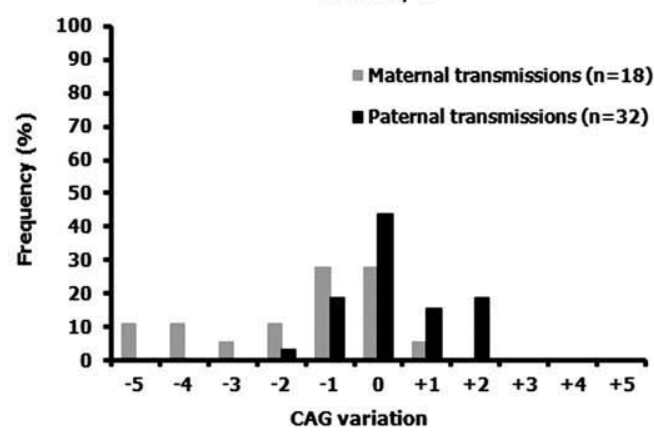

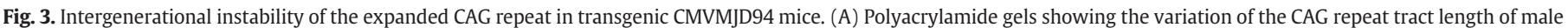

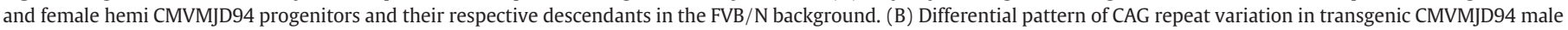
and female meioses, in the $\mathrm{FVB} / \mathrm{N}$ and $\mathrm{C} 57 \mathrm{Bl} / 6$ genetic backgrounds.

units shorter, did not present any behavioral differences in comparison with control littermates (Figs. 4A,B).

Although the expression of normal ATXN3 in mouse could in theory give rise to some pathological consequences, other transgenic mice expressing the same protein were indistinguishable from wildtype mice, even when considering mouse lines with strong expression and mice of older ages (between 12 and 22 months) (Bichelmeier et al., 2007; Cemal et al., 2002; Chou et al., 2008; Goti et al., 2004). In view of these findings, we used wild-type littermates as controls. Furthermore, homo CMVMJD83 mice did not present motor phenotype or brain pathology (see below) although they expressed levels of expanded ATXN3 similar to those of hemi CMVMJD94 mice. Since transgenic CMVMJD83 mice carried a shorter CAG tract than the CMVMJD94 ones (83 vs. 94 CAGs), these data allowed us to conclude that at this level of expression of expanded ATXN3, the minimum CAG tract length to induce an altered phenotype in the transgenic mice is between 84 and 94 CAG repeats.

Interestingly, the usage of two different study groups, including hemi CMVMJD94 mice and their non-transgenic littermates for phenotype assessment, revealed that although, at 16 weeks of age, the first group of hemizygous animals displayed a significant decrease in the time spent on the accelerating rod (mean of 4 trials, 4-40 rpm), the hemizygous mice from the second group did not replicate this motor deficit at the same age (Fig. 5A). Since transgenic mice displayed CAG instability across generations, we hypothesized that CAG repeat length differences could have influenced the manifestation of the disease at early stages. In fact, we observed that hemizygous animals from group II carried lower CAG repeat lengths (mean $95.85 \pm 1.73$ ) than animals from group I (mean 97.61 \pm 2.00 ) (Fig. 5B). Additionally, when analyzing all of the data, we found an inverse correlation between the CAG tract length and the time spent on the rod at 16 weeks of age $(p<0.05)$ : animals carrying longer CAG repeats spent less time on the rod (Fig. 5B). This genotype-phenotype correlation is in agreement with that observed in MJD patients
(Maciel et al., 1995) and with the anticipation phenomenon, in which longer repeat lengths in successive generations are associated with a more severe and earlier onset of symptoms.

\section{Neuronal atrophy and astrogliosis in transgenic CMVMJD94 mice}

Histopathological observations of brain sections of transgenic CMVMJD94 mice revealed the presence of scattered dark, shrunken cells with basophilic cytoplasm (Fig. 6) (H\&E staining) in several regions, such as the dentate, pontine nuclei and thalamus, in comparison with normal cells observed in wild-type animals (Fig. 6). Globally, these findings are consistent with the pathological findings reported in MJD patients, where the degeneration involves atrophy and gliosis (Kanda et al., 1989; Rub et al., 2008). To further investigate the molecular mechanism of neurodegeneration, we performed a TUNEL assay, as well as caspase-3 IHC and fluoro-jade staining in brain sections of CMVMJD94 mice with no positive results (data not shown). These results suggest that the dark neurons observed in such areas, as the thalamus and pontine and dentate nuclei could be dying via another cell death process, or, alternatively, that their morphology could be associated with a dysfunctional but not a dying cell status. Nevertheless, CMVMJD94 transgenic mice with 49 weeks of age displayed an increase in GFAP immunostaining (within reactive astrocytes) in specific areas, such as the vestibular nuclei (Ve) and substantia nigra (SN), indicative of an abnormal increase in the number of astrocytes in these areas, a phenomenon normally associated with neuronal demise (Figs. 7A-F; Supp. Figure 3). The analysis of CMVMJD94 mice brains at early stages of the disease ( 16 weeks) revealed the presence of a milder neuronal atrophy in areas such as the pontine and dentate nuclei (Fig. 6) and the absence of the astrogliosis observed at late stages. Our results direct us to a different concept of neurodegeneration, encompassing a progressive degradation of neuronal function and structure that may include cellular changes, such as loss of synaptic contacts, disruption 
A

\section{$24 \mathrm{rpm}$}

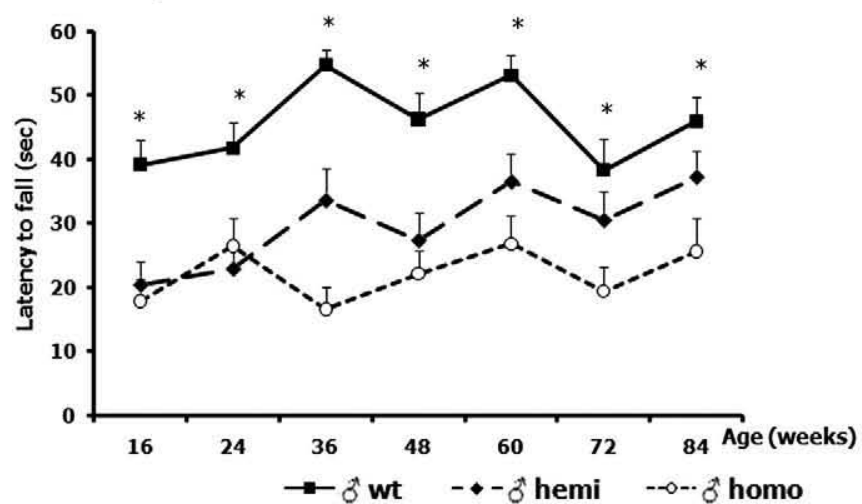

CMVMJD94
4-40 rpm

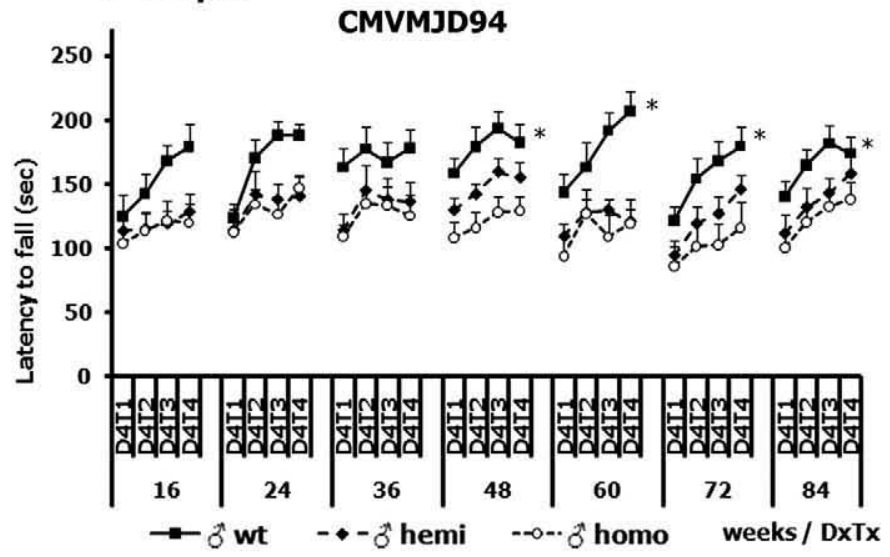

B

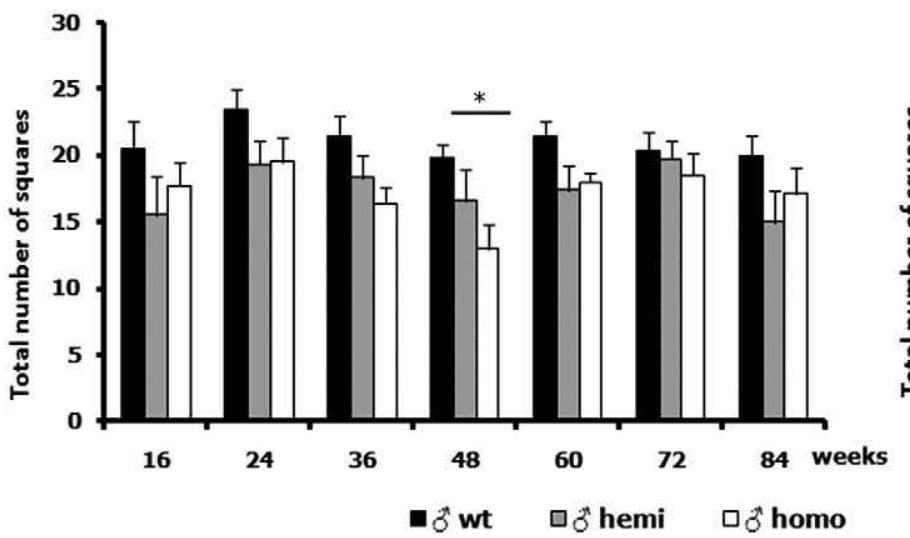

24 rpm

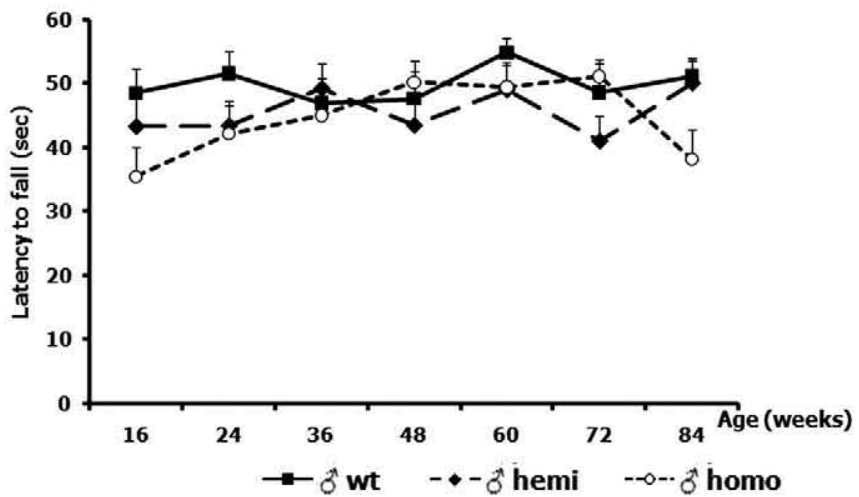

4-40 rpm

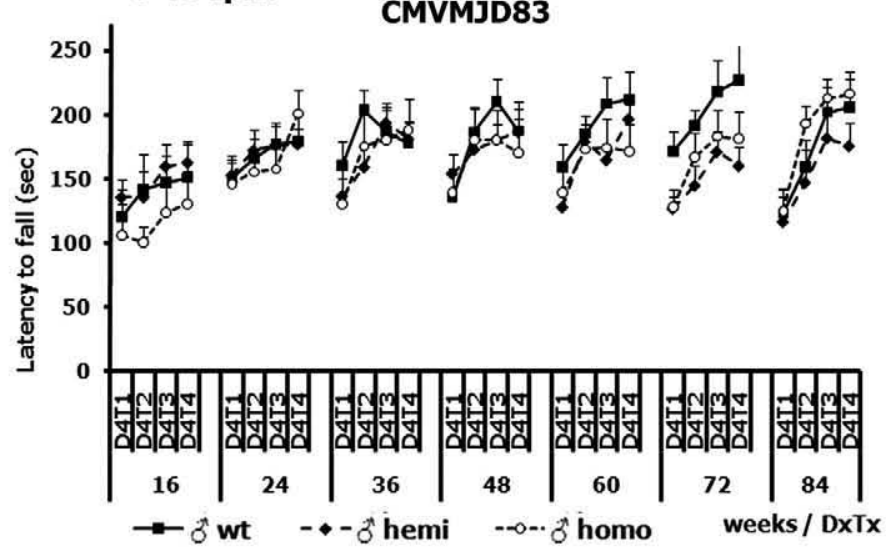

CMVMJD83

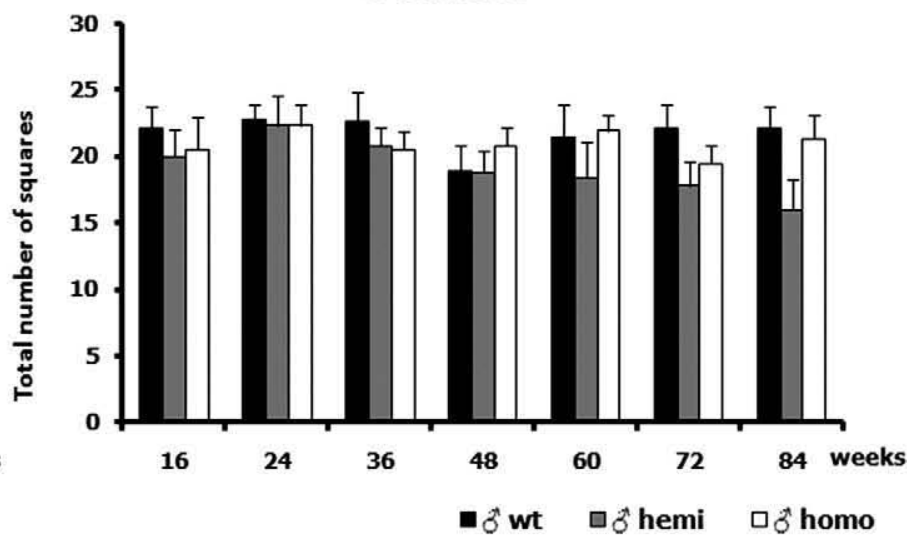

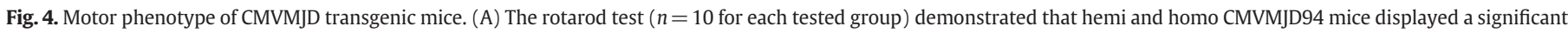

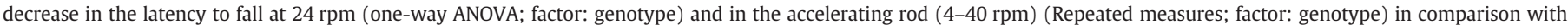

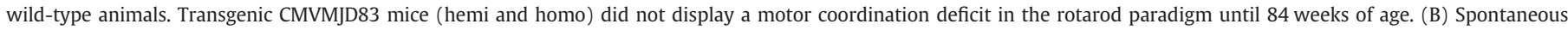

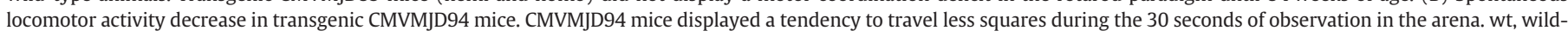
type; hemi, hemizygous; homo, homozygous. *Statistical significance $p<0.05$.

of axonal transport, blockage of autophagy and mitochondrial dysfunction, among others. Although this process can eventually lead to cell death through different pathways, it is by itself sufficient to cause neurological disease.

Although it has been suggested that a cleavage product of mutant ATXN3 is critical for the induction of MJD pathogenesis (Wellington et al., 1998), western blot analysis of brains from symptomatic transgenic CMVMJD94 mice, did not reveal the presence of the $36 \mathrm{kDa}$ cleavage product of ATXN3, described previously in human (endstage) patients and in another mouse model (Goti et al., 2004).
Additionally, anti-ataxin-3 IHC in the brain of these MJD transgenic mice demonstrated that the protein was mainly localized in punctuate structures in the perinuclear region of neurons (Fig. 2), and no large intranuclear inclusions were found even at late stages (84 weeks of age). These results suggest that the disease manifestation in our transgenic mice is not dependent on the formation of nuclear inclusions. In fact, although cytoplasmic and/or nuclear inclusions in neurons of the CNS represent a pathological hallmark of polyQs diseases (Yamada et al., 2000), several studies have demonstrated a dissociation between the presence of large protein inclusions and 

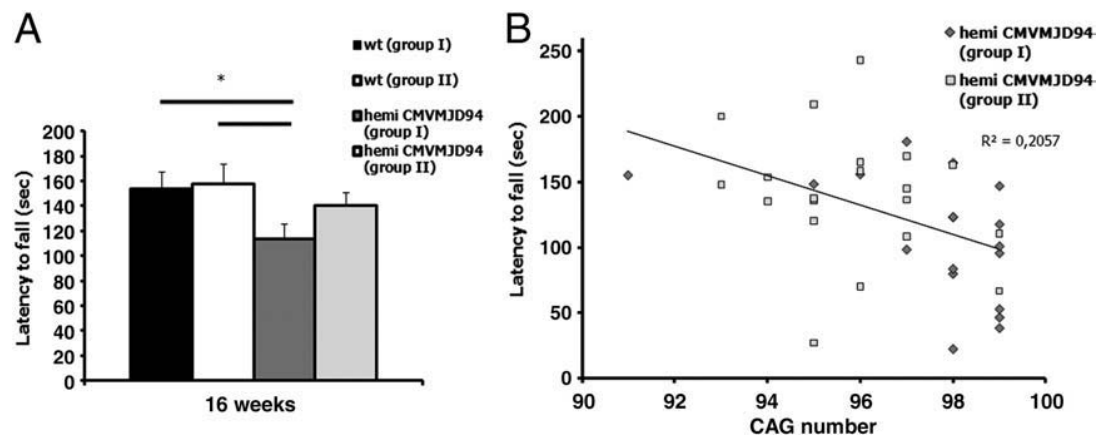

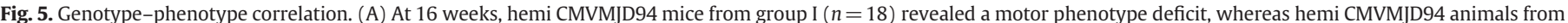

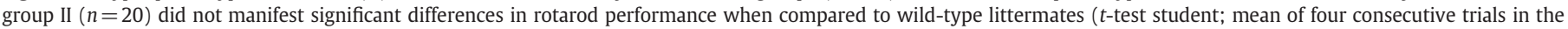

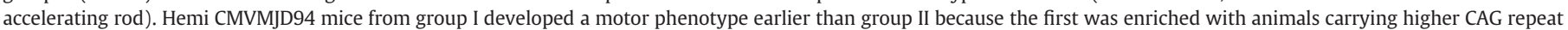

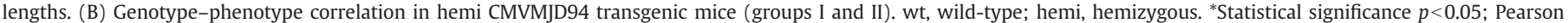
correlation $R^{2}=0.2057 ; p=0.004$.

toxicity in vivo (Klement et al., 1998; Reiner et al., 2007; Slow et al., 2005) and in vitro (Arrasate et al., 2004; Saudou et al., 1998). Furthermore, recent findings using a Spinal and Bulbar Muscular Atrophy (SBMA) mouse model have implicated the species corresponding to the earlier stages of polyQ protein aggregate formation - oligomers - in the disease progression (Li et al., 2007).

Tissue- and age-dependent somatic mosaicism of the CAG repeat

The hypothesis that somatic mosaicism of the CAG repeat may contribute to the specificity of neurodegeneration (Telenius et al. 1994) was previously tested by determining the mosaicism index of the CAG repeat tract in various brain regions of MJD patients (Cancel et al., 1998; Lopes-Cendes et al., 1996; Tanaka et al., 1999). Our analysis of the CAG repeat size in several brain regions and different peripheral tissues of the CMVMJD94 mice showed the existence of somatic mosaicism of the expanded allele - several bands larger and smaller than the major band were observed (Fig. 8A). The mosaicism index $(\mathrm{MI})$ of the $(\mathrm{CAG})_{\mathrm{n}}$ tract in different brain regions (cerebellar cortex, deep cerebellar nuclei, motor cortex, hippocampus, amygdala, hypothalamus, substantia nigra, striatum and pontine nuclei) and peripheral tissues (heart, skeletal muscle, testis, kidney, liver and tail) was determined with aging (Fig. 8). An age-dependent increase in the mosaicism index (ANOVA, factor age, $p<0.05$ ) was observed in all tissues that were analyzed, except for the heart (Fig. 8B). In addition, it was possible to observe the $\mathrm{MI}$ increase during aging in successive tail DNA samples from the same animal (Fig. 8A). Our results are in accordance with those obtained in animal models of different polyQ diseases, in which age has been described as a CAG repeat instability modifier (Clark et al., 2007; Ishiguro et al., 2001; Sato et al., 1999). Interestingly, we also observed that different tissues exhibited different patterns of MI increase with age. The cells from the liver,
16 weeks

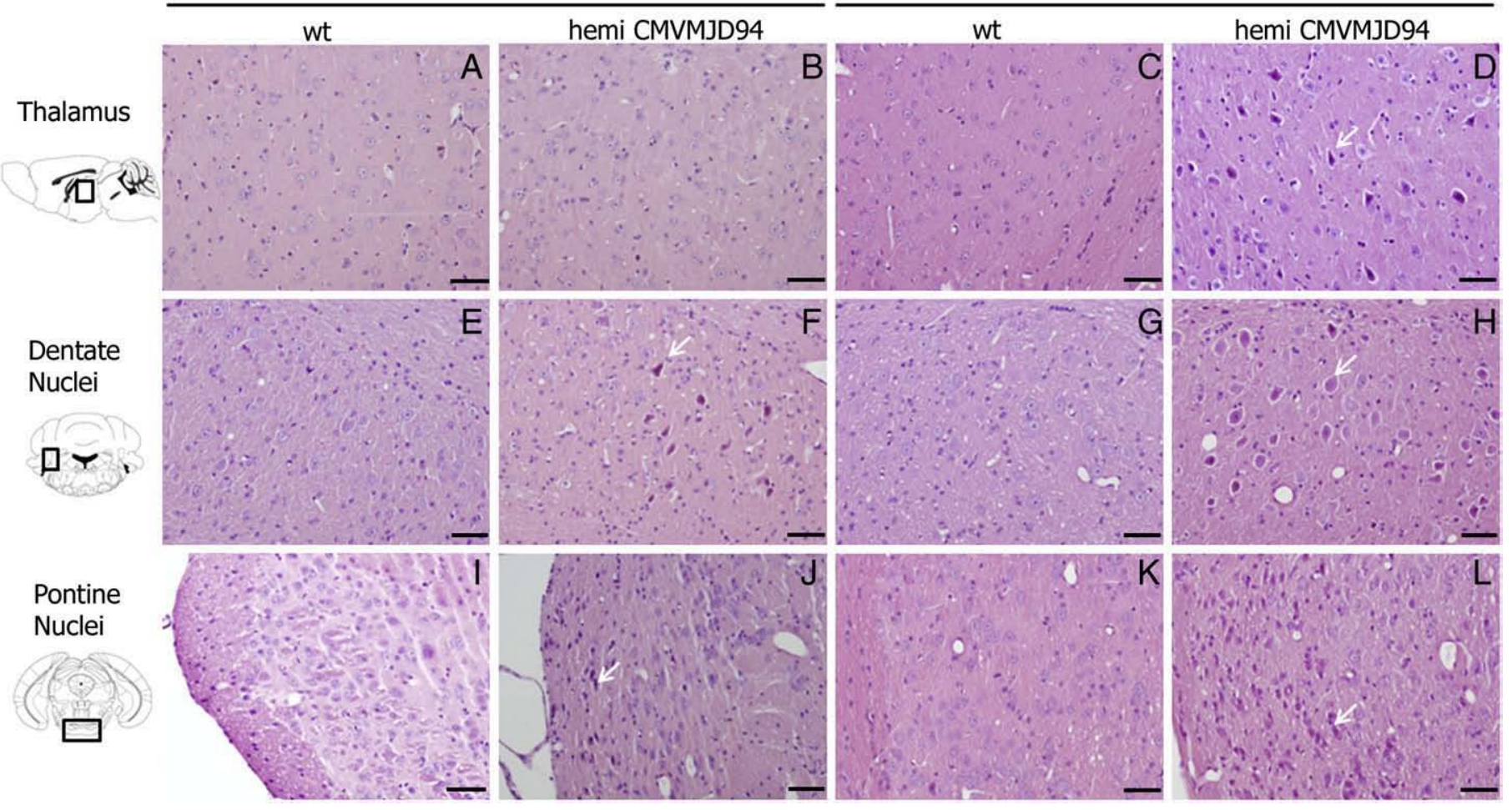

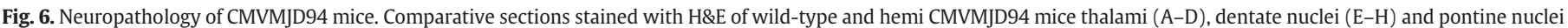

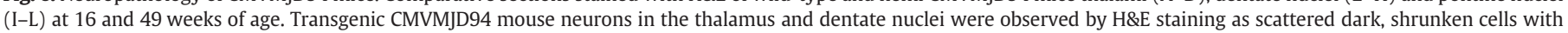
pyknotic nuclei and a basophilic cytoplasm (arrows) in comparison with normal cells observed in wild-type animals. wt, wild-type; hemi, hemizygous. Scale bar: $50 \mu$ m. 


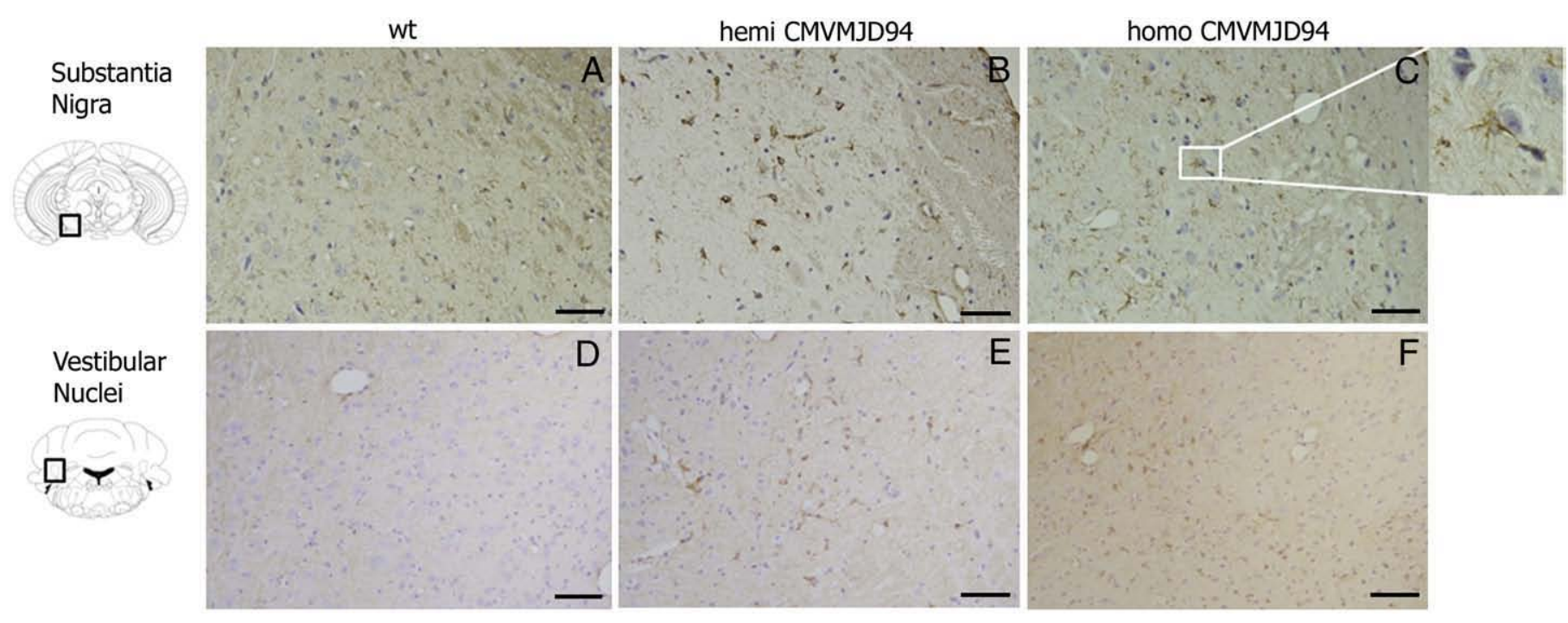

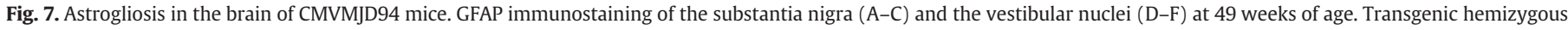

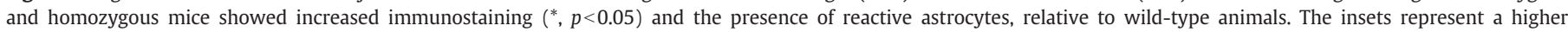
magnification demonstrating both atrophic neurons and reactive astrocytes. wt, wild-type; hemi, hemizygous; homo, homozygous. Scale bar: $50 \mu \mathrm{m}$.

pontine nuclei, substantia nigra and striatum displayed the highest MI increase, and the cells from the cerebellar cortex and skeletal muscle showed the lowest MI increase during aging. These results are in agreement with the behavior of the mutant allele in the human patients, in which the cerebellar cortex and skeletal muscle exhibited a lesser degree of CAG instability, while the liver displayed a greater diversity of bands (Tanaka et al., 1999). Although mitotic turnover may contribute largely to the tissue-specific pattern of mosaicism in MJD, the absence of a direct correlation of the MI with the mitotic rate of the cells of the tissues analyzed (e.g., liver and pontine nuclei) suggests that other unknown cell-specific factors should be taken into consideration to understand the mechanism of somatic mosaicism in CAG repeat diseases.

Among the brain regions analyzed, the pontine nuclei, substantia nigra and striatum were the areas with the highest MI increase during aging; of these, we observed pathological involvement in the pontine nuclei and substantia nigra (described above) but not in the striatum, which led us to conclude that, in this mouse model, the specific increase of somatic mosaicism was not clearly correlated with neuronal vulnerability. Although a correlation between somatic mosaicism and the pathology of different brain regions was not evident, our results concerning the $(C A G)_{n}$ size variation pattern in CMVMJD94 transgenic mice revealed that this mouse model can be useful for the study of the molecular basis of the CAG repeat instability as well as of MJD pathogenesis.

Absence of neuroinflammation in CMVMJD94 mice before the onset of the disease and at early symptomatic stages

The idea of chronic and detrimental microglial neuroinflammation as a cause of neurodegeneration has been studied extensively in the context of neurodegenerative diseases, notably in Alzheimer's disease (Streit et al., 2004), but nothing is known about the role of neuroinflammation in MJD pathogenesis. According to this theory, activated microglia, as the main cellular source of inflammatory mediators in the CNS, gain neurotoxic properties leading to neuronal death (McGeer and McGeer, 2001, 2002).

Previous results demonstrated that genes associated with inflammation are upregulated in expanded ataxin-3-expressing cell lines and in post-mortem MJD brains (Evert et al., 2001). However, the authors discussed the difficulty associated with deciding whether this inflammation is an essential step in the pathogenesis, or whether it is a compensatory response to maintain cellular function and integrity. Moreover, they suggested that it is unlikely that the reported changes represent an early event in the pathophysiology of MJD, because upregulation of pro-inflammatory genes was observed at a time when NIs were already present.

In order to clarify the role of neuroinflammation in the pathogenesis of MJD, we evaluated microglial cell morphology in the cerebellum of wild-type and CMVMJD94 transgenic mice prior to the onset of the disease manifestation ( 10 weeks), at early ( 25 weeks) and late stages of disease (109 weeks). We did not find any differences in Iba-1 staining at any studied age between transgenic and control groups (Fig. 9A; Supp. Figure 4A). In agreement, the Iba-1 expression levels as measured by qRT-PCR in the cerebellum of transgenic animals did not differ from wild-type animals, as expected if microglia cells were activated (Fig. 9B; Supp. Figure 4B). Additionally, the gene expression levels of TNF, interleukin-1 $\beta$ and interleukin6 did not differ between control and transgenic mice (Fig. 9B; Supp. Figure 4B). Among the additional 84 genes related to the inflammatory response that we analyzed in the cerebella of CMVMJD94 and control mice at 8 and 24 weeks of age, only six were significantly (but very slightly) altered in the transgenic mice: at 8 weeks we observed a downregulation of integrin $1 \beta(0.66$ fold change; $p=0.026)$ and at 24 weeks an upregulation of the chemokines Ccl4 (2.31 fold change; $p=0.041$ ) and $\mathrm{CxCl} 10$ (2.02 fold change; $p=0.015)$ and a downregulation of IL13 receptor $\alpha 1(0.83$ fold change; $p=0.043)$, Il10 receptor $\alpha 1$ ( 0.73 fold change; $p=0.034$ ) and Lymphotoxin B ( 0.60 fold change; $p=0.047$ ) (Supplementary table). The biological relevance of these subtle changes is not clear, but we conclude that an overall pro-inflammatory pattern is not present

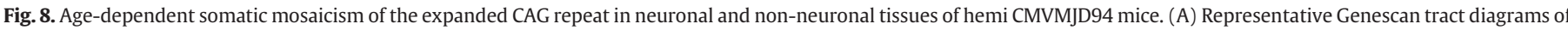

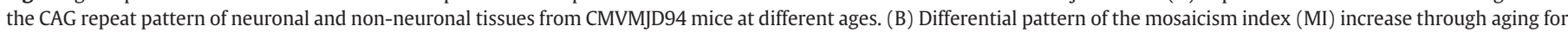
transgenic CMVMJD94 mice. The average of the MI for at least three mouse samples of each tissue is represented $( \pm$ SEM). *Statistical significance $p<0.05$. 

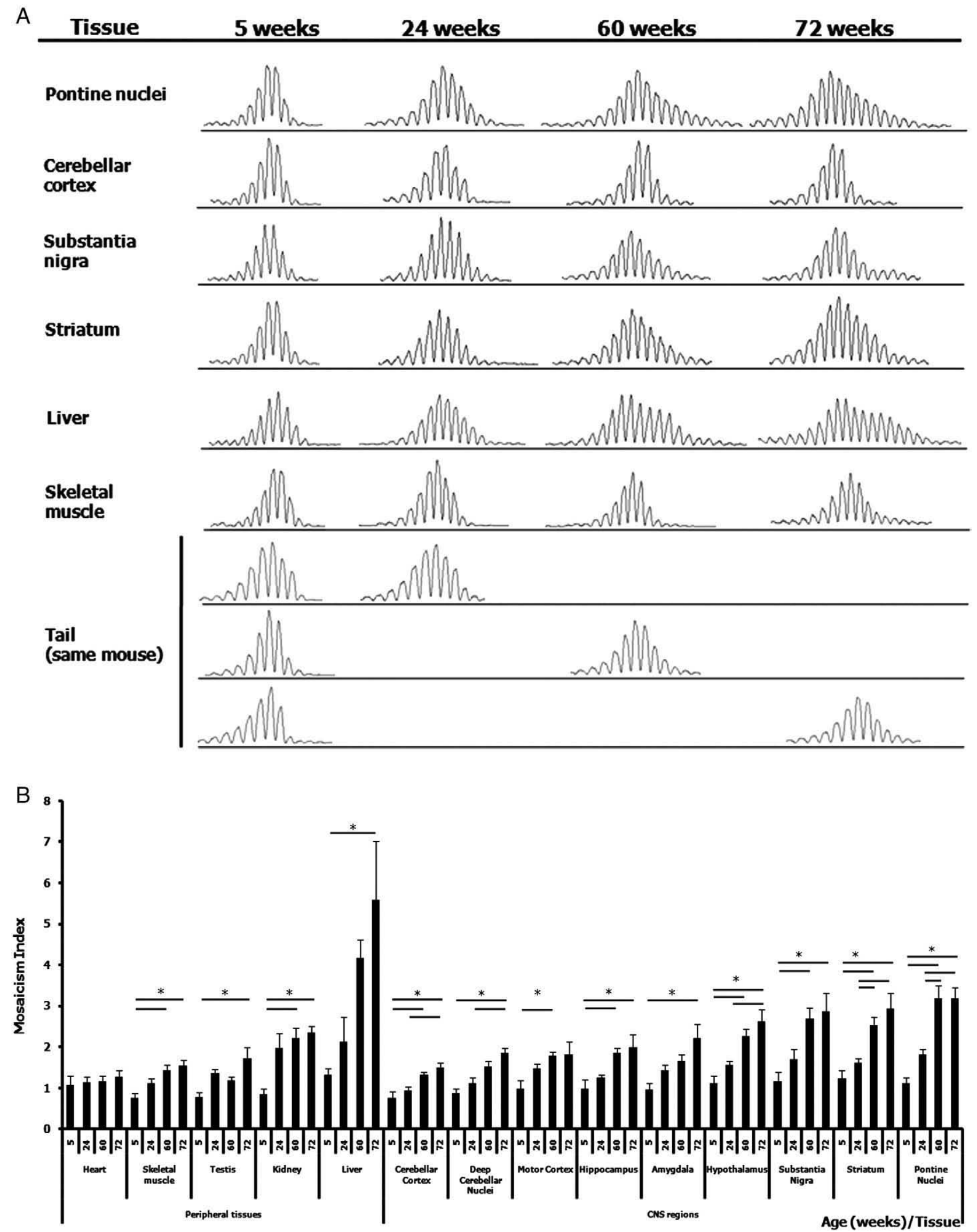
A wt hemi CMVMJD94
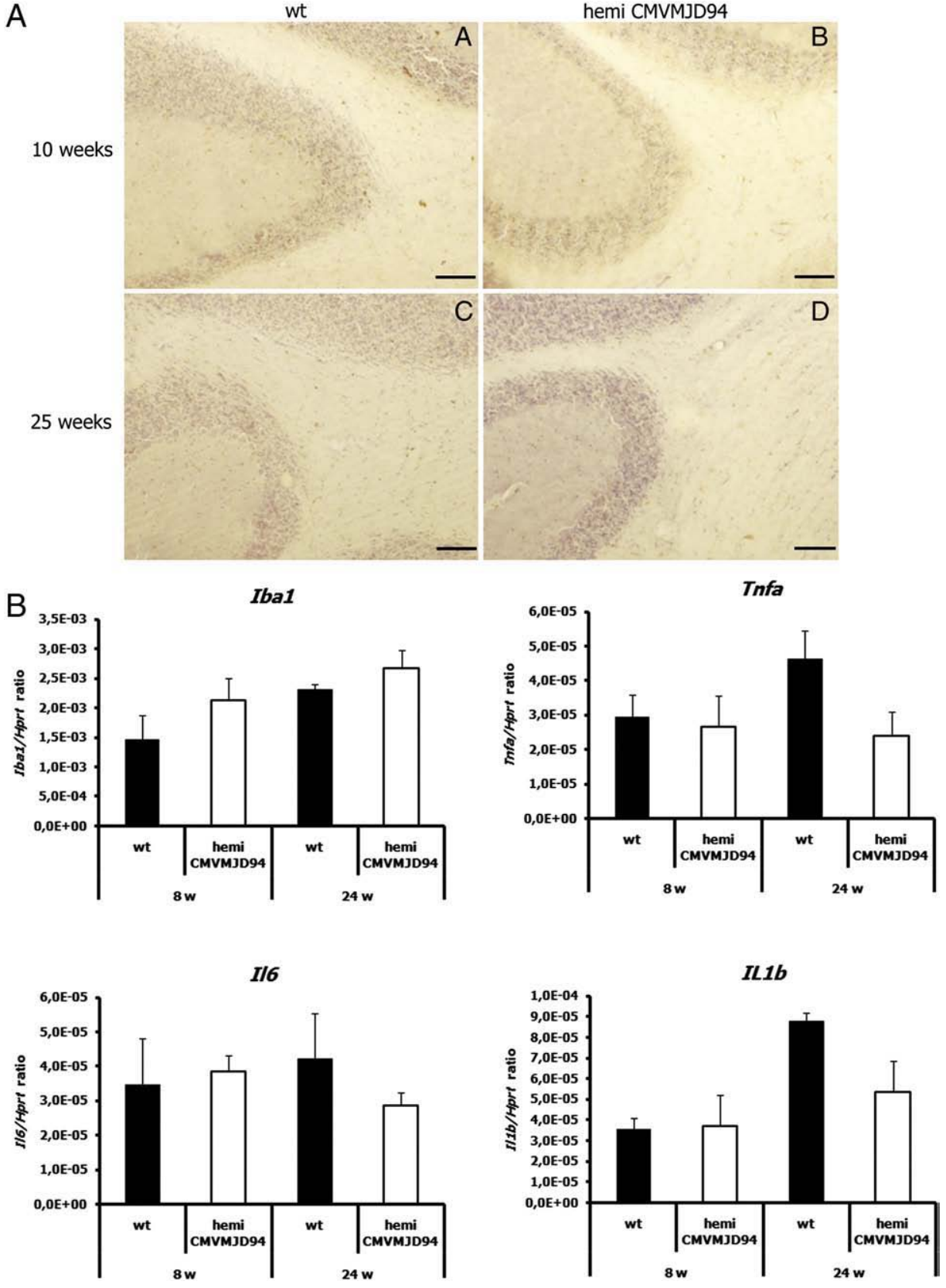

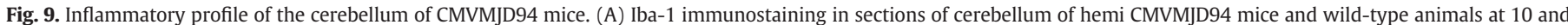

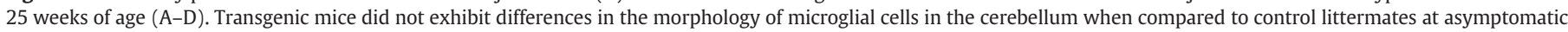

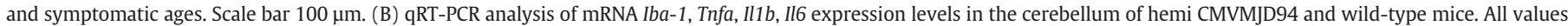
were normalized for the Hprt1 gene. wt, wild-type; hemi, hemizygous.

at these early stages in the cerebellum of CMVMJD94 transgenic mice. Our results thus suggest that microglial cells are not primed for activation before the onset of the MJD disease, which implies that the microglial activation observed in post-mortem tissues (Evert et al., 2001) could be a consequence rather than a cause of the long neurodegeneration process undergone by human patients.

In summary, this work provides evidence for a dominant CAG length-dependent neurological phenotype in the novel CMVMJD94 transgenic mouse model, in agreement with that observed in human patients. Moreover, we show that this mouse model recapitulates key features of the human disorder: CAG repeat instability, neurological dysfunction and brain pathology. The neuronal dysfunction occurs in the absence of ATXN3 cleavage products, intranuclear inclusions, or any evidence of programmed cell death, necrosis or neuroinflamma- tion, which might occur at later stages of the disease. We propose that this model is useful for dissecting the initial cellular and molecular events in the pathogenesis of MJD.

\section{Acknowledgments}

We would like to thank to Dr. Henry Paulson for providing the anti-ataxin-3 serum, Dr. Mónica Sousa for the pCMV vector and to Eng. Lucília Goreti Pinto for technical assistance. A.S-F., M.C.C., S.S. and C.B. received FCT fellowships (SFRH/BD/15910/2005; SFRH/BPD/ 28560/2006; PTDC/SAU-GMG/64076/2006; SFRH/BPD/20987/2004). This research was funded by Fundação para a Ciência e Tecnologia through projects FEDER/FCT, POCI/SAU-MMO/60412/2004, PTDC/ SAU-GMG/64076/2006; and Ataxia MJD Research Project. 


\section{Appendix A. Supplementary data}

Supplementary data associated with this article can be found, in the online version, at doi:10.1016/j.nbd.2010.05.021.

\section{References}

Arrasate, M., Mitra, S., Schweitzer, E.S., Segal, M.R., Finkbeiner, S., 2004. Inclusion body formation reduces levels of mutant huntingtin and the risk of neuronal death. Nature 431, 805-810.

Bichelmeier, U., Schmidt, T., Hubener, J., Boy, J., Ruttiger, L., Habig, K., Poths, S., Bonin, M., Knipper, M., Schmidt, W.J., Wilbertz, J., Wolburg, H., Laccone, F., Riess, O., 2007. Nuclear localization of ataxin-3 is required for the manifestation of symptoms in SCA3: in vivo evidence. J. Neurosci. 27, 7418-7428.

Boy, J., Schmidt, T., Schumann, U., Grasshoff, U., Unser, S., Holzmann, C., Schmitt, I., Karl, T. Laccone, F., Wolburg, H., Ibrahim, S., Riess, O., 2009a. A transgenic mouse model of Spinocerebellar Ataxia Type 3 resembling late disease onset and gender-specific instability of CAG repeats. Neurobiol. Dis. 37, 284-293.

Boy, J., Schmidt, T., Wolburg, H., Mack, A., Nuber, S., Bottcher, M., Schmitt, I., Holzmann, C., Zimmermann, F., Servadio, A., Riess, O., 2009b. Reversibility of symptoms in a conditional mouse model of Spinocerebellar Ataxia Type 3. Hum. Mol. Genet. 18 4282-4295.

Cancel, G., Gourfinkel-An, I., Stevanin, G., Didierjean, O., Abbas, N., Hirsch, E., Agid, Y., Brice, A., 1998. Somatic mosaicism of the CAG repeat expansion in spinocerebellar ataxia type 3/Machado-Joseph disease. Hum. Mutat. 11, 23-27.

Carter, R.J., Lione, L.A., Humby, T., Mangiarini, L., Mahal, A., Bates, G.P., Dunnett, S.B. Morton, A.J., 1999. Characterization of progressive motor deficits in mice transgenic for the human Huntington's disease mutation. J. Neurosci. 19, 3248-3257.

Cemal, C.K., Carroll, C.J., Lawrence, L., Lowrie, M.B., Ruddle, P., Al-Mahdawi, S., King, R.H., Pook, M.A., Huxley, C., Chamberlain, S., 2002. YAC transgenic mice carrying pathological alleles of the MJD1 locus exhibit a mild and slowly progressive cerebellar deficit. Hum. Mol. Genet. 11, 1075-1094.

Chou, A.H., Yeh, T.H., Ouyang, P., Chen, Y.L., Chen, S.Y., Wang, H.L., 2008. Polyglutamineexpanded ataxin- 3 causes cerebellar dysfunction of SCA3 transgenic mice by inducing transcriptional dysregulation. Neurobiol. Dis. 31, 89-101.

Clark, R.M., De Biase, I., Malykhina, A.P., Al-Mahdawi, S., Pook, M., Bidichandani, S.I., 2007. The GAA triplet-repeat is unstable in the context of the human FXN locus and displays age-dependent expansions in cerebellum and DRG in a transgenic mouse model. Hum. Genet. 120, 633-640.

Costa, M.C., Gomes-da-Silva, J., Miranda, C.J., Sequeiros, J., Santos, M.M., Maciel, P., 2004 Genomic structure, promoter activity, and developmental expression of the mouse homologue of the Machado-Joseph disease (MJD) gene. Genomics 84, 361-373.

Coutinho, P., Andrade, C., 1978. Autosomal dominant system degeneration in Portuguese families of the Azores Islands. A new genetic disorder involving cerebellar, pyramidal, extrapyramidal and spinal cord motor functions. Neurology 28, 703-709.

Evert, B.O., Vogt, I.R, Kindermann, C., Ozimek, L, de Vos, R.A., Brunt, E.R., Schmitt, I, Klockgether, T., Wullner, U., 2001. Inflammatory genes are upregulated in expanded ataxin-3-expressing cell lines and spinocerebellar ataxia type 3 brains. J. Neurosci. 21, 5389-5396.

Ferro, A., Carvalho, A.L., Teixeira-Castro, A., Almeida, C., Tome, R.J., Cortes, L., Rodrigues, A.J., Logarinho, E., Sequeiros, J., Macedo-Ribeiro, S., Maciel, P., 2007. NEDD8: a new ataxin-3 interactor. Biochim. Biophys. Acta 1773, 1619-1627.

Goti, D., Katzen, S.M., Mez, J., Kurtis, N., Kiluk, J., Ben-Haiem, L., Jenkins, N.A., Copeland, N.G., Kakizuka, A., Sharp, A.H., Ross, C.A., Mouton, P.R., Colomer, V., 2004. A mutant ataxin-3 putative-cleavage fragment in brains of Machado-Joseph disease patients and transgenic mice is cytotoxic above a critical concentration. J. Neurosci. 24 10266-10279.

Goto, J., Watanabe, M., Ichikawa, Y., Yee, S.B., Ihara, N., Endo, K., Igarashi, S., Takiyama, Y., Gaspar, C., Maciel, P., Tsuji, S., Rouleau, G.A., Kanazawa, I., 1997. Machado-Joseph disease gene products carrying different carboxyl termini. Neurosci. Res. 28 373-377.

Grewal, R.P., Cancel, G., Leeflang, E.P., Durr, A., McPeek, M.S., Draghinas, D., Yao, X. Stevanin, G., Alnot, M.O., Brice, A., Arnheim, N., 1999. French Machado-Joseph disease patients do not exhibit gametic segregation distortion: a sperm typing analysis. Hum. Mol. Genet. 8, 1779-1784.

Ikeda, H., Yamaguchi, M., Sugai, S., Aze, Y., Narumiya, S., Kakizuka, A., 1996. Expanded polyglutamine in the Machado-Joseph disease protein induces cell death in vitro and in vivo. Nat. Genet. 13, 196-202.

Ikeuchi, T., Igarashi, S., Takiyama, Y., Onodera, O., Oyake, M., Takano, H., Koide, R. Tanaka, H., Tsuji, S., 1996. Non-Mendelian transmission in dentatorubralpallidoluysian atrophy and Machado-Joseph disease: the mutant allele is preferentially transmitted in male meiosis. Am. J. Hum. Genet. 58, 730-733.

Ishiguro, H., Yamada, K., Sawada, H., Nishii, K., Ichino, N., Sawada, M., Kurosawa, Y., Matsushita, N., Kobayashi, K., Goto, J., Hashida, H., Masuda, N., Kanazawa, I., Nagatsu, T., 2001. Age-dependent and tissue-specific CAG repeat instability occurs in mouse knock-in for a mutant Huntington's disease gene. J. Neurosci. Res. 65, 289-297.

Iughetti, P., Otto, P.A., Zatz, M., Passos Bueno, M.R., Marie, S.K., 1998. Different behavior in the paternally vs maternally inherited mutated allele in Brazilian MachadoJoseph (MJD1) families. Am. J. Med. Genet. 77, 246-248.

Kanda, T., Isozaki, E., Kato, S., Tanabe, H., Oda, M., 1989. Type III Machado-Joseph disease in a Japanese family: a clinicopathological study with special reference to the peripheral nervous system. Clin. Neuropathol. 8, 134-141.
Kawaguchi, Y., Okamoto, T., Taniwaki, M., Aizawa, M., Inoue, M., Katayama, S., Kawakami, H., Nakamura, S., Nishimura, M., Akiguchi, I., 1994. CAG expansions in a novel gene for Machado-Joseph disease at chromosome 14q32.1. Nat. Genet. 8, 221-228.

Klement, I.A., Skinner, P.J., Kaytor, M.D., Yi, H., Hersch, S.M., Clark, H.B., Zoghbi, H.Y., Orr, H.T., 1998. Ataxin-1 nuclear localization and aggregation: role in polyglutamineinduced disease in SCA1 transgenic mice. Cell 95, 41-53.

Li, M., Chevalier-Larsen, E.S., Merry, D.E., Diamond, M.I., 2007. Soluble androgen receptor oligomers underlie pathology in a mouse model of spinobulbar muscular atrophy. J. Biol. Chem. 282, 3157-3164.

Lopes-Cendes, I., Maciel, P., Kish, S., Gaspar, C., Robitaille, Y., Clark, H.B., Koeppen, A.H., Nance, M., Schut, L., Silveira, I., Coutinho, P., Sequeiros, J., Rouleau, G.A., 1996. Somatic mosaicism in the central nervous system in spinocerebellar ataxia type 1 and Machado-Joseph disease. Ann. Neurol. 40, 199-206.

Maciel, P., Gaspar, C., DeStefano, A.L., Silveira, I., Coutinho, P., Radvany, J., Dawson, D.M., Sudarsky, L., Guimaraes, J., Loureiro, J.E., et al., 1995. Correlation between CAG repeat length and clinical features in Machado-Joseph disease. Am. J. Hum. Genet. 57, 54-61

Maciel, P., Lopes-Cendes, I., Kish, S., Sequeiros, J., Rouleau, G.A., 1997. Mosaicism of the CAG repeat in CNS tissue in relation to age at death in spinocerebellar ataxia type 1 and Machado-Joseph disease patients. Am. J. Hum. Genet. 60, 993-996.

Maciel, P., Costa, M.C., Ferro, A., Rousseau, M., Santos, C.S., Gaspar, C., Barros, J., Rouleau, G.A., Coutinho, P., Sequeiros, J., 2001. Improvement in the molecular diagnosis of Machado-Joseph disease. Arch. Neurol. 58, 1821-1827.

McGeer, P.L., McGeer, E.G., 2001. Inflammation, autotoxicity and Alzheimer disease. Neurobiol. Aging 22, 799-809.

McGeer, P.L., McGeer, E.G., 2002. Inflammatory processes in amyotrophic lateral sclerosis. Muscle Nerve 26, 459-470.

Nicklas, W., Baneux, P., Boot, R., Decelle, T., Deeny, A.A., Fumanelli, M., Illgen-Wilcke, B., 2002. Recommendations for the health monitoring of rodent and rabbit colonies in breeding and experimental units. Lab Anim. 36, 20-42.

Paulson, H.L., Das, S.S., Crino, P.B., Perez, M.K., Patel, S.C., Gotsdiner, D., Fischbeck, K.H., Pittman, R.N., 1997. Machado-Joseph disease gene product is a cytoplasmic protein widely expressed in brain. Ann. Neurol. 41, 453-462.

Rafael, J.A., Nitta, Y., Peters, J., Davies, K.E., 2000. Testing of SHIRPA, a mouse phenotypic assessment protocol, on $\mathrm{Dmd}(\mathrm{mdx})$ and $\mathrm{Dmd}(\mathrm{mdx} 3 \mathrm{cv})$ dystrophin-deficient mice. Mamm. Genome 11, 725-728.

Reiner, A., Del Mar, N., Deng, Y.P., Meade, C.A., Sun, Z., Goldowitz, D., 2007. R6/2 neurons with intranuclear inclusions survive for prolonged periods in the brains of chimeric mice. J. Comp. Neurol. 505, 603-629.

Riess, O., Epplen, J.T., Amoiridis, G., Przuntek, H., Schols, L., 1997. Transmission distortion of the mutant alleles in spinocerebellar ataxia. Hum. Genet. 99, 282-284.

Rogers, D.C., Fisher, E.M., Brown, S.D., Peters, J., Hunter, A.J., Martin, J.E., 1997. Behavioral and functional analysis of mouse phenotype: SHIRPA, a proposed protocol for comprehensive phenotype assessment. Mamm. Genome 8, 711-713.

Romanul, F.C., Fowler, H.L., Radvany, J., Feldman, R.G., Feingold, M., 1977. Azorean disease of the nervous system. N Engl J. Med. 296, 1505-1508.

Rosenberg, R.N., Nyhan, W.L., Bay, C., 1976. Autosomal dominant striatonigral degeneration: a clinical, pathological, and biochemical study of a new genetic disorder. Trans. Am. Neurol. Assoc. 101, 78-80.

Rub, U., Brunt, E.R., Deller, T., 2008. New insights into the pathoanatomy of spinocerebellar ataxia type 3 (Machado-Joseph disease). Curr. Opin. Neurol. 21, 111-116.

Sato, T., Oyake, M., Nakamura, K., Nakao, K., Fukusima, Y., Onodera, O., Igarashi, S., Takano, H., Kikugawa, K., Ishida, Y., Shimohata, T., Koide, R., Ikeuchi, T., Tanaka, H., Futamura, N., Matsumura, R., Takayanagi, T., Tanaka, F., Sobue, G., Komure, O., Takahashi, M., Sano, A., Ichikawa, Y., Goto, J., Kanazawa, I., et al., 1999. Transgenic mice harboring a full-length human mutant DRPLA gene exhibit age-dependent intergenerational and somatic instabilities of CAG repeats comparable with those in DRPLA patients. Hum. Mol. Genet. 8, 99-106.

Saudou, F., Finkbeiner, S., Devys, D., Greenberg, M.E., 1998. Huntingtin acts in the nucleus to induce apoptosis but death does not correlate with the formation of intranuclear inclusions. Cell 95, 55-66.

Slow, E.J., Graham, R.K., Osmand, A.P., Devon, R.S., Lu, G., Deng, Y., Pearson, J., Vaid, K., Bissada, N., Wetzel, R., Leavitt, B.R., Hayden, M.R., 2005. Absence of behavioral abnormalities and neurodegeneration in vivo despite widespread neuronal huntingtin inclusions. Proc. Natl. Acad. Sci. U. S. A. 102, 11402-11407.

Sobue, G., Doyu, M., Nakao, N., Shimada, N., Mitsuma, T., Maruyama, H., Kawakami, S., Nakamura, S., 1996. Homozygosity for Machado-Joseph disease gene enhances phenotypic severity. J. Neurol. Neurosurg. Psychiatry 60, 354-356.

Streit, W.J., Mrak, R.E., Griffin, W.S., 2004. Microglia and neuroinflammation: a pathological perspective. J. Neuroinflammation 1, 14 .

Takiyama, Y., Sakoe, K., Soutome, M., Namekawa, M., Ogawa, T., Nakano, I., Igarashi, S., Oyake, M., Tanaka, H., Tsuji, S., Nishizawa, M., 1997. Single sperm analysis of the CAG repeats in the gene for Machado-Joseph disease (MJD1): evidence for nonMendelian transmission of the MJD1 gene and for the effect of the intragenic CGG/ GGG polymorphism on the intergenerational instability. Hum. Mol. Genet. 6, 1063-1068.

Tanaka, F., Ito, Y., Sobue, G., 1999. Somatic mosaicism of expanded CAG trinucleotide repeat in the neural and nonneural tissues of Machado-Joseph disease (MJD). Nippon Rinsho 57, 838-842.

Telenius, H., Kremer, B., Goldberg, Y.P., Theilmann, J., Andrew, S.E., Zeisler, J., Adam, S., Greenberg, C., Ives, E.J., Clarke, L.A., et al., 1994. Somatic and gonadal mosaicism of the Huntington disease gene CAG repeat in brain and sperm. Nat. Genet. 6, 409-414.

van Alfen, N., Sinke, R.J., Zwarts, M.J., Gabreels-Festen, A., Praamstra, P., Kremer, B.P., Horstink, M.W., 2001. Intermediate CAG repeat lengths $(53,54)$ for MJD/SCA3 are associated with an abnormal phenotype. Ann. Neurol. 49, 805-807. 
Wallace, J.E., Krauter, E.E., Campbell, B.A., 1980. Motor and reflexive behavior in the aging rat. J. Gerontol. 35, 364-370.

Wellington, C.L., Ellerby, L.M., Hackam, A.S., Margolis, R.L., Trifiro, M.A., Singaraja, R., McCutcheon, K., Salvesen, G.S., Propp, S.S., Bromm, M., Rowland, K.J., Zhang, T., Rasper, D., Roy, S., Thornberry, N., Pinsky, L., Kakizuka, A., Ross, C.A., Nicholson, D.W., Bredesen, D.E., Hayden, M.R., 1998. Caspase cleavage of gene products associated with triplet expansion disorders generates truncated fragments containing the polyglutamine tract. J. Biol. Chem. 273, 9158-9167.
Williams, L.C., Hegde, M.R., Herrera, G., Stapleton, P.M., Love, D.R., 1999. Comparative semi-automated analysis of (CAG) repeats in the Huntington disease gene: use of internal standards. Mol. Cell. Probes 13, 283-289.

Woods, B.T., Schaumburg, H.H., 1972. Nigro-spino-dentatal degeneration with nuclear ophthalmoplegia. A unique and partially treatable clinico-pathological entity. J. Neurol. Sci. 17, 149-166.

Yamada, M., Tsuji, S., Takahashi, H., 2000. Pathology of CAG repeat diseases Neuropathology 20, 319-325. 